[Aus dem hygienischen Institut zu Breslau.]

\title{
Kritische und experimentelle Beiträge zur hygienischen Beurtheilung des Wassers. ${ }^{1}$ \\ Von
}

Dr. W. Kruse,

Pripatdozenten für Hygiene,

Assistenten des hygienischen Instituț in Bonn, früher in Breslau.

Vier Methoden der Beurtheilung sind es, die sich im Lauf der Entwickelung unserer Kenntnisse von der hygienischen Brauchbarkeit des Wassers herausgebildet haben.

Die Beobachtung, dass ein Theil der zum Genusse dienenden Wässer gute, ein anderer Theil schlechte Wirkungen zu entfalten schien, musste zunächst dazu führen, die Oertlichkeit, aus dem das Wasser entnommen wurde, dafür verantwortlich zu machen. Diese auf den einzelnen Fall gegründeten Ortheile konnten sich kaum zu allgemeinen Kriterien entwickeln; doch hat ein Satz in der populären medicinischen Erfahrung fast aller Völker eine anerkannte Bedeutung gehabt, nämlich der, dass der Genuss ron Sumpfwasser die Entstehung von Wechselfiebern begünstige. Wir werden weiterhin sehen, wie sich die heutige wissenschaftliche Erfahrung zu dieser alten Lehre stellt.

Naturgemäss sucht man weiter nach objectiven Kennzeichen der Güte eines Wassers, als solche bieten sich gewisse einfachste physiologische Eigenschaften desselben dar, nämlich seine Einwirkungsart auf den Gesichts-, Geruchs-, Geschmacks- und Temperatursinn. Instinctiv ziehen wir von Wässern, die entgegengesetzte sinnfällige Eigenschaften besitzen, das klare dem trüben, das Geruch und Geschmack nicht beleidigende dem übelriechenden und schlechtschmeckenden, das kühle dem lauwarmen vor. Der Gedanke liegt nahe genug, dass die Natur uns damit wichtige

${ }^{1}$ Eingegangen am 15. December 1893. 
hygienische Kriterien für die Brauchbarkeit eines Wassers an die Hand gegeben habe. So beschränken sich denn auch die Ansprüche, die Plinius an das Wasser stellt, auf diese Forderungen unserer Sinne.

Einen wissenschaftlichen Fortschritt gegenüber der physiologischen bedeutet die chemische Beurtheilungsmethode, indem sie wenigstens versucht, die Wirkungen des Wassers aus seinen Bestandtheilen zu erklären. Einfachste Thatsachen aus der Chemie des Wassers konnten schon früh erschlossen werden ausseinem wechselndenVerhalten beim Kochen und Waschen. Die Entwickelung der Wissenschaft hat erst viel später zur Erklärung dieser alten Erfahrungen geführt. In den letzten drei Jahrzehnten wurden die neu geschaffenen chemischen Untersuchungsmethoden im weitesten Umfang für die hygienische Praxis verwendet. Man glaubte in der stofflichen Zusammensetzung des Wassers einen sicheren Maassstab für seine Zuträglichkeit gefunden zu haben. Es war dies die Epoche, in der chemische Grenzzahlen für das hygienisch zulässige Wasser aufgestellt wurden. Eine unbestreitbare Thatsache lag dieser Theorie zu Grunde, nämlich die, dass gewisse zweifellos zuträgliche Wässer eines bestimmten Ursprungs, Quellwässer, nur innerhalb gewisser Grenzen in ihrer Zusammensetzung schwankten, dass hingegen Wässer anderer Herkunft, wie Fluss- und Grundwässer, von denen manche in gerechtem Verdachte standen, Krankheiten erzeugen zu können, unter sich und gegenüber den Quellwässern erheblich variirten. Man ging aber viel zu weit, indem man das Urtheil, das für einige Beispiele dieser Kategorie gelten mochte, auf die ganze Gruppe ausdebnte. Es liegt das an nichts Anderem als an der Unvollkommenheit der chemischen Betrachtungsweise, die zwischen verdächtigen und nicht verdächtigen, zwischen schädlichen und unschädlichen Wässern eben nicht unterscheiden kann. Trotzdem sich diese Erkenntniss in wissenschaftlichen Kreisen mehr und mehr Bahn gebrochen hat, schleppt sich die Hygiene nach wie vor in Theorie und Praxis mit dem ganzen Ballast der chemischen Untersuchungsmethoden des Wassers. Nun wäre es ja nicht weiter verwunderlich, wenn nur das Publicum woch in jenem alten Vorurtbeil befangen wäre, dass die chemische Untersuchung über Werth und Unwerth eines Brunnens zu entscheiden habe, leider ist aber auch ein grosser Theil der Aerzte und Sanitätsbeamten auf demselben Standpunkte stehen geblieben. Wenn man sich in der Fachlitteratur umsieht, so begegnet man freilich ebenso oft einer bemerkenswerthen Unsicherheit des Urtheils. Gründe für eine wesentliche Bedeutung der chemischen Zusammensetzung des Wassers laann man zwar nicht angeben, aber doch pflegt man einen gewissermasser geheimnissvollen Einfluss von Stoffen, die der „,Verwesung“, der „Fäulniss" ihren Ursprung verdanken, nicht abzuleugnen. 
Diejenige neue Methode, die der chemischen unzweifelhaft den Vorrang abgelaufen hat, wollen wir die mikroskopische nennen. Schon lange bevor man gelernt hatte, Krankheitserreger durch das Mikroskop nachzuweisen, haben Aerzte das Vorhandensein specifischer Krankheitsursachen und zwar organischer Natur im Allgemeinen und ihr Vorkommen im Wasser im Besonderen vermuthet. Wir begegnen sogar der Vorstellung, dass solehe von aussen in Brunnen hineingelangen könnten, und weiter der nur logischen F́lgerung, dass die letzteren gegen solche Verunreinigungen geschützt werden müssten. Diese Forderung, die wunderlicher Weise von gewisser Seite als neue Entdeckung aufgestellt wird, enthält den wichtigsten Lehrsatz der Hygiene des Wassers. Freilich ist die Bedeutung desselben nicht immer klar erkannt worden. Su gab es eine Zeit - es war die der beginnenden bakteriologischen Technik wo allein die Gegenwart zahlreicher Mikroorganismen im Wasser schon genügte, um dessen Brauchbarkeit zum Genuss in Abrede zu stellen. Später und vielfach noch heute wurde die Zahl und die Art der im Wasser vorkommenden Bakterien nur als Index einer stattgehabten Verunreinigung desselben betrachtet und daraufhin Grenzzahlen, auch für die bakteriologische Beschaffenheit eines Wassers aufgestellt. Der Kernpunkt der Frage, einer specifischen Verunreinigung des Wassers, wurde tadurch einigermassen verrückt. Allerdings waren die Bemühungen, die Krankheitserreger selbst im Wasser nachzuweisen, ursprünglich nur von sehr schwachem Erfolg begleitet; auch schien die experimentelle Behandlung der Aufgabe, die Lebensfähigkeit der specifischen Bakterien im Wasser zu prüfen, zu dem Ergebniss zu führen, dass von einer länger dauernden Conservirung derselben ebenda nicht die Rede sein könne. Es konnte dies Resultat in gewissem Grade als Stütze für die Ansicht derjenigen betrachtet werden, die überhaupt eine Uebertragbarkeit von Infectionskrankheiten durch das Wasser leugneten. Die allerletzte Zeit hat in diesem Stand der Dinge eine sehr wesentliche Aenderung bewirkt. Ein von der Natur im Grossen ausgeführtes Experiment hat nicht nur die Möglichkeit der Infection durch Wasser bewiesen, sondern die Verrollkommnung der Untersuchungsmethode hat auch in vielen Fällen den directen Nachweis der Krankheitserreger in dem verdächtigen Medium gestattet und erlaubt, das Problem von Neuem experimentell in Angriff zu nehmen.

Man kann wohl sagen, dass gerade nach diesen letzten epidemiologischen Erfahrungen die Frage der Versorgung unserer Wohnstätten mit Wasser allseitig eine erhöhte Würdigung erfahren hat. Die Verwaltungen grosser wie kleiner Gemeinwesen zeigen sich erfreulicher Weise bemüht, bestehende Missstände nach Kräften zu beseitigen. Vom Staate und ron den praktischen Hygienikern wird es abhängen, sich diese populäre 
Strömung in rechtem Sinne zu Nutze zu machen. Gerade im jetzigen Zeitpunkt scheint es erwünscht, durch kritische Sonderung den Besitzstand der hygienischen Wissenschaft auf diesem Gebiete genau festzustellen und soweit als möglich die sich ergebenden Deficits durch neue experimentelle Beiträge auszufüllen.

I.

Bevor es eigentliche Untersuchungsmethoden des Wassers gab, war man darauf angewiesen, auf den Ursprung desselben das wesentliche Gewicht zu legen, um seine verschiedene Wirkung verständlich zu finden. Heutzutage betrachten wir die letztere nur als Function der physiologischen, chemischen und mikroskopischen Eigenschaften des Wassers. Die Localität, 'der eine Quelle entspringt, kommt nur soweit in Betracht, als sie diese Eigenschaften bedingt. Wir schreiten deswegen sofort zur Besprechung der letzteren im Einzelnen. Erst dann werden wir in der Lage sein, zu beurtheilen, ob etwa Wässer, die einen ähnlichen Ursprung haben, z. B. die Grundwässer, in gewissen allgemeinen hygienischen Charakteren übereinstimmen und sich von Wässern anderen Ursprungs, z. B. Flusswässern, unterscheiden.

II.

Als̀ die wesentlichsten Kriterien für die hygienische Brauchbarkeit eines Wassers können dessen physiologische Eigenschaften nicht betrachtet werden. Denn eine irgend erhebliche Krankheit wird durch den üblen Eindruck desselben auf den Gesichts-, Geschmacks-, Geruchsund Temperatursinne niemals hervorgerufen. Höchstens können durch Ekelgefühl vorübergehende Zustände von Unwohlsein bewirkt werden, und auch das nur bei dem extremsten Grade der in Rede stehenden Eigenschaften oder bei besonders empfindlichen Personen. Immerhin beeinträehtigt eine für die Sinne unangenehme Beschaffenheit des Trinkwassers in jedem Falle dessen Geniessbarkeit. Die Folgen davon entbehren nicht ganz des hygienischen Interesses. Einerseits ist das Wasser als Nahrungsmittel unentbehrlich, andererseits kann es, wenn es appetitlich ist, als billiges und zugleich gesundes Genussmittel von Werth sein. Wird seine Geniessbarkeit durch sinnfällige üble Eigenschaften herabgesetzt, so wird der Consument bestrebt sein, es auf andere Weise zu ersetzen. Die Ersatzmittel können aber durchaus unhygienische sein. Wir brauchen dabei nicht allein an alkoholische Getränke zu denken, sondern auch an Eis oder einfach bloss anderes Wasser aus verdächtigen Quellen. Nehmen wir z. B. den Fall ·an, dass einer Stadt durch die Wasserleitung zwar ein gegen das Hineingelangen von Infectionsstoffen ausreichend geschütztes, aber zum Genuss nicht einladendes Wasser zugeführt werde - im Sommer verdient z. B. ein auch tadellos filtrirtes Fluss- 
wasser diese Bezeichnung wegen seiner lauen Temperatur. Wie kann der besser Situirte die mangelnde Frische des Wassers ersetzen? Wenn er einige hygienisch richtige Vorstellungen hat und über die nöthigen Mittel verfügt, wird er künstlich in Eis gekühltes Wasser trinken. Sehr häufig aber wird er, um dem momentanen Bedürfniss schnell abzuhelfen, einfach ein Stück Eis in das Wasser hineinthun, ohne an die eventuellen Gefahren zu denken, die mit dem Genuss von vielen Eissorten einhergehen. Was thut der Arbeiter, der einen kühlen Trunk haben will? Er nimmt statt des unverdächtigen, aber warmen Leitungswassers ein kühles aber möglicher Weise inficirtes Brunnenwasser. Es ist wahr, dass im Allgemeinen für den einzelnen Fall nicht viele Chancen einer Infection bestehen, wenn man aber bedenkt, dass in den heissen Sommermonaten bei Weitem die meisten Einwohner unserer Grossstädte täglich mehrmals sich vor die Wahl gestellt sehen, ob sie ihrem Bedürfniss nach einem kühlen Trunke auf diesem oder jenem Wege genügen sollen, so wird man meinem Beispiel doch nicht die praktische Bedeutung versagen. Für die Wahl desselben sind gerade bestimmte Erfahrungen, die ich neuerdings bei einer Typhusepidemie in Breslau gemacht habe, entscheidend gewesen. Im Uebrigen ist die Frage der Wasserversorgung nicht bloss eine rein hygienische, sondern in gewissem Sinne auch eine ästhetische und sociale. Jede Stadtverwaltung wird auch, abgesehen von allen hygienischen Bedenken, die gegen ein unappetitliches Wasser sprechen können, ein Opfer nicht scheuen, wenn sie dadurch in der Lage ist, der Bevölkerung im Trinkwasser nicht nur ein ungefährliches Nahrungsmittel, sondern zugleich auch ein köstliches Genussmittel zu bieten.

Die einzelnen sinnfälligen Figenschaften des Wassers sind nicht ron derselben Bedeutung, theils weil sie in verschiedenem Grade der Verbesserung fähig sind, theils weil sich ihre Wirkung in ungleichem Maasse durch Angewöhnung abstumpfen kann. Gegen den schlechten Geruch des Wassers hat man kaum ein Mittel, ein schlechter Geschmack kann durch geringe Zusätze verbessert, grobe Trübungen durch Absetzenlassen oder Filtration beseitigt, zu niedrige Temperatur verhältnissmässig ohne Schwierigkeit, zu hohe nur, wo ausreichende Mittel zur Verfügung stehen, leicht und schnell ausgeglichen werden. An ein trübes Aussehen, auch an einen Beigeschmack des Wassers gewöhnen wir uns ziemlich leicht, die Gewöhnung bestimmt oft sogar in der Weise das Urtheil, dass ein ursprünglich unangenehm anmuthender Beigeschmack eines Wassers gegenüber der Geschmacklosigkeit eines anderen Wassers geradezu als Vorzug empfunden wird. Man gewöhnt sich zwar auch daran, ein Wasser, dessen Temperatur im Sommer lauwarm ist, zu trinken, weil es schliesslich auch den Durst löscht, das Gefühl der Erfrischung vermisst man jedoch stets bei Genuss desselben. 
Ein Gesichtspunkt verdient noch besondere Beachtung, nämlich derjenige der teleologischen Zweckmässigkeit, die den besprochenen physiologischen Eigenschaften des Wassers innewohnen könnte. Sind etwa die letzteren als Indices für andere hygienisch wichtige dem Wasser zukommende Qualitäten zu betrachten? Die Antwort ist leider eine völlig verneinende. Nehmen wir z. B. die Trübungen, die im Wasser vorkommen. Bestehen sie, wie so häufig, aus thonigen Beimengungen, so sind sie völlig unschädlich; bestehen sie aus ausgefallenem Eisenoxydhydrat, so deuten sie freilich darauf hin, dass das Wasser zum dauernden Genuss nicht geeignet ist; sind sie endlich wesentlich organisirter Natur, was übrigens nur bei stehenden Wässern vorkommen dürfte, so ist eventuell schón ein einmaliger Genuss des Wassers von üblen Folgen begleitet; ist aber überhaupt keine Trübung vorhanden - so kann jede der drei Möglichkeiten bestehen! Geruch, Geschmack und Temperaturverhältnisse sind im Allgemeinen noch weniger bezeichnend. Spuren ron Schwefelwasserstoff werden noch als lästig empfunden, die für die Gesundheit absolut keine Bedeutung haben; der Geschmack nach Eisen besteht noch bei ganz minimalem Gehalt des Wassers an diesem Stoffe; höchstens kann man vielleicht die Empfindung der allzu niedrigen Temperatur eines Wassers als Warnung vor dessen Benutzung ansehen. Man'sieht also, welche Sicherheit unser Urtheil über ein Wasser haben würde, wenn wir nur auf unsere Sinne angewiesen wären.

III.

Die chemische Untersuchung giebt uns in einzelnen Beziehungen sicherere Kriterien an die Hand, lässt uns freilich in den wichtigsten Punkten im Stich. Wir wollen mit den anorganischen Substanzen, die im Wasser vorkommen, und zwar mit denjenigen beginnen, deren Schädlichkeit allgemein anerkannt ist: es sind das Blei-, Arsen- und in sehr seltenen Fällen auch Kupferverbindungen, die aus gewerblichen $A b$ wässern oder dem Material der Leitungen stammen. Deren Nachweis im W़asser erfolgt nach den allgemeinen Regeln der Chemie und hat kaun Schwierigkeiten.

Ein viertes Metall, das Eisen, hat praktisch für die Wasserbeurtheilung eine grōssere Bedeutung, obwohl es lange nicht so gefährlich ist, als die genannten Stoffe. Eisen ist in einer Kategorie ron Wässern, nämlich im Grundwasser gewisser Gegenden, speciell in der norddeutschen Tiefebene sehr verbreitet. Hygienische Berücksichtigung verdient es erstens. weil es dem Wasser einen unangenehmen Geschmack und durch Ausfällung an der Luft ein trübes, gelbes, unappetitliches Aussehen verleiht, zweitens, weil ein dauernder Genuss eisenhaltigen Wassers bei empfindlichen 
Personen zu Verdauungsstörungen führen kann. Die procentualen Grenzen, in denen dieser gesundheitsschädliche Einfluss noch zu Tage tritt, müssten übrigens erst festgestellt werden. In der Praxis der Wasserversorgung haben bisher nicht diese hygienische Rücksichten von der Verwendung eisenhaltigen Grundwassers abgehalten, sondern wesentlich ökonomische Nachtheile, die mit dem Gebrauch in den Haushaltungen verbunden sind und die schlechten Erfahrungen, die man an den Leitungsröhren unter der Einwirkung. solchen Wassers gemacht hat. Bekanntlich begünstigt dasselbe in ausserordentlichem Maasse die Wucherung eines Pilzes, der Crenothrix Kühniana, dessen dichte Rasen die Ursache von Röhrenverstopfungen werden. Es war das ein Grund, der es längere Zeit unmöglich machte, an eine Wasserversorgung vieler norddeutscher Städte durch Grundwasser zu denken. Neuerdings scheint diese Schwierigkeit dadurch überwunden zu sein, dass man Verfahren ersonnen hat, das Eisen, bevor das Wasser in die Leitungen gelangt, zu entfernen. Wir selbst haben uns an einigen Privatanlagen hier in Breslau überzeugen können, dass selbst ein sehr erheblicher Gehalt an Eisen, 20 bis $30^{\mathrm{mg}}$ pro Liter, durch das neue Piefkesche Lüftungsverfahren völlig entfernt wird. Es wäre wichtig, auch für kleinere Brunnen eine praktische Einrichtung zur Enteisenung zu haben. Versuche in dieser Richtung sind in der Nähe von Breslau gemacht worden, indem man neben dem eigentlichen Brunnenschacht ein Reservoir angelegt hat, in dem eine Durchlüftung des Wassers und Filtration stattfinden sollte. Bisher sind die Ergebnisse nicht zufriedenstellend gewesen, da die Enteisenung nicht eine vollständige war.

Salze der alkalischen Erdmetalle sind regelmässige Bestandtheile aller Wässer und zwar in viel höheren Procentverhältnissen als die der genannten Metalle. Ihre physiologische Wirkung ist aber auch eine viel geringere. Als die differentesten gelten das schwefelsaure Calcium, sowie das salpetersaure and chlorwasserstoffsaure Magnesium (C. Schmidt). Das erstere ist namentlich in Quellen enthalten, die aus gypshaltigen Formationen entspringen, die beiden letzteren im Grundwasser, das durch „Stadtlauge" verunreinigt ist. Alle Erdsalze, nur die genannten vorzugsweise, scheinen in grösseren Mengen die Verdauungsorgane zu belästigen, insbesondere Diarrhöen herrorzurufen. Diese Beobachtungen sind so oft und an so verschiedenen Orten gemacht, dass man wohl an ihrer Richtigkeit nicht zweifeln darf. Stets wird freilich ron den Autoren bemerkt, dass die Angewöhnung bald die schädliche Wirkung solcher Wässer ausgleiche, daher denn nur bei eben zugereisten Fremden oder überhaupt bei Personen, die ihr Trinkwasser wechseln, ein Einfluss desselben beobachtet werde. Die hygienische Bedeutung der Erdsalze im Wasser wird natürlich dadurch erheblich beschränkt. Was die Zahlen für den Gehalt des 
Wassers an Erdsalzen anlangt, so nehmen die Wiener Wasserversorgungscommission (1864) und Reichardt $180^{\mathrm{mg}}$ Kalk im Liter Wasser, Tie-


$20^{\circ}$ als äusserste zulässige Grenze an. Lehmann lässt beim Trinkwasser eine noch grössere Härte von $30^{\circ}$ und mehr zu. Nehmen wir diese Zahl für Quellwässer als Maximum an, so können wir für Grundwässer, die durch Stadtlauge verunreinigt sind, noch weitere Grenzen setzen, denn hier sind es statt der stark wirkenden schwefelsauren Salze meist nur salpeter- und kohlensaure Verbindungen der Erdmetalle, die in Frage kommen. Allerdings kommen nun in jeder Stadt Brunnenwässer genug vor, die 50 ja 80 Härtegrade haben. Die Erfahrung lehrt, dass auch diese von den regelmässigen Consumenten gut vertragen werden, wir würden daher in dem hohen Salzgehalt allein keinen Grund finden, ihre Brauchbarkeit rom hygienischen Standpunlite aus zu bestreiten. Eine andere Sache ist es aber, ob wir dieselben Wässer z. B. beim Drohen einer Epidemie nicht daran gewöhnten Personen empfehlen könnten, wenn sie sich auch aus anderen Gründen, z. B. wegen tadelloser Anlage der betreffenden Brunnen, dazu eignen möchten. Ich glaube, dass in diesem Fall der Wechsel des Wassers als solcher eine Gefahr bedeuten kann, die nicht zu unterschätzen ist. Wir würden durch dieselbe Maassnahme auf der einen Seite durch Hervorrufen einer Magen- und Darmverstimmung eine Disposition zur specifischen Erkrankung erzeugen, während wir auf der anderen die Möglichkeit einer Aufnahme des Infectionserregers abzuschneiden suchen.

Von den Wirkungen der Erdsalze auf den Magendarmeanal des Menschen ganz abgesehen, verdienen die letzteren noch von einem anderen Gesichtspunkte aus unsere Berücksichtigung. Die Thatsache, dass die Härte eines Wassers, d.h. die Summe der in demselben enthaltenen Salze der alkalischen Erden, auch für die Zwecke des Haushalts, für Waschen und Kochen von Bedeutung ist, hat unmittelbar nur ein ökonomisehes Interesse. Mittelbar nimmt aber auch die Hygiene einen Antheil daran. Wir sehen das namentlich in dem Falle, wenn eine Bevölkerung die Möglichkeit hat, seinen Bedarf auf zwei verschiedenen Wegen, z. B. mit einem weichen Fluss- oder einem harten Brunnenwasser zu befriedigen. Die ökonomischen Nachtheile des letzteren geben allzu leicht die Veranlassung dazu, dass man seine hygienischen Vorzüge hintansetzt, Vorzüge, die, wie wir weiterhin sehen werden, namentlich in der Richtung der Verhütung von Infectionskrankheiten liegen.

Nur historischen Werth haben noch die Vorstellungen über Zusammenhang der Härte des Trinkwassers mit dem Auftreten ron Kropf, Kretinismus und Harnsteinen.

Was den Nachweis der in dem Wasser enthaltenen Verbindungen 
alkalischer Erden anbetrifft, so haben wir die für hygienische wie ökonomische Zwecke völlig genügende Methode der Seifenbestimmung. Es handelt sich ja hier immer nur um Annäherungswerthe und diese werden leicht und schnell gewonnen.

Den Alkalien, die im Wasser vorhanden sind, wird von jeher nur eine geringe Bedeutung beigelegt, auch in den grössten Mengen die praktisch in Betracht kommen, sind sie unschädlich und spielen nicht einmal die Rolle von Factoren, die die Appetitlichkeit des Wassers bestimmen.

Die Säuren, an die die Metalle gebunden sind, sind gesundheitlich als indifferent zu betrachten, nur in ihren Verbindungen mit alkalischen Erden scheinen sie, wie oben besprochen, gewisse nicht gleichgültige Wirkungen ausüben zu können. Um so mehr. Werth hat man seit Langem auf die indirecten Beziehungen gelegt, die sie zu der Bodenverunreinigung haben sollen. Die Chlorwasserstoffsäure in erster Linie, dann Salpeterund Schwefelsäure sind als Indicatoren der Verunreinigung des Grundwassers durch die in den Boden eindringenden Abfallstoffe des menschlichen Haushaltes zu betrachten.

Dieser Satz ist durch die hygienisch-chemischen Forschungen der letzten Jahrzehnte festgestellt. Es fragt sich nur, ob diese „Verunreinigung" Substanzen in das Wasser hineinbringt, die die Gesundheit in irgend einer Weise zu schädigen geeignet sind. Geben wir auch ohne Weiteres zu, dass solche Stoffe in den Abwässern, wenn sie den Boden tränken, vorhanden sein können, so folgt daraus noch nicht, dass sie auch in dem Wasser, das vermittelst Filtration durch die Erde bis zum Grundwasser hindurch gedrungen ist, enthalten sind. Dieselben Forschungen haben ja mit Bestimmtheit erwiesen, dass auf dem Wege von der Oberfläche zum Grundwasser eine ganze Reihe von Veränderungen mit dem filtrirenden Wasser vor sich gehen. Die Unschädlichkeit der anorganischen Verbindungen, auch jener Indicatoren selbst, wird eingeräumt, es kämen also nur organische und organisirte Gifte als etwa gefährliche Bestandtheile der Abfallstoffe in Betracht. Wir werden weiter unten zu prüfen haben, wie sich dieselben bei dem Filtrationsprocess im Boden verhalten.

Der Ursprung der genannten drei Säuren ist, wie bekannt, ein verschiedener. Das Chlor ist an Alkali gebunden schon in den Abwässern enthalten, die Schwefelsäure ist in letzteren wenigstens zum Theil schon vorgebildet und ist zum anderen Theile im Boden selbst aus der Oxydation des organischen Schwefels der Abfallstoffe entstanden - ein dritter Theil, der durch Auslaugung des im Boden selbst enthaitenen Gypses in das Grundwasser gelangt, ist inconstant - nur die Salpetersäure entsteht vollständig im Boden aus den stickstoffhaltigen Bestandtheilen der Abwässer. Man kann sie daher zugleich als einen Maassstab der in den Boden ein- 
dringenden Verunreinigung und der in letzterem vor sich gehenden Umwandlung der verunreinigenden. Stoffe betrachten.

Neben der Salpetersäure sind häufig im Wasser kleine Mengen von salpetriger Säure und Ammoniak vorhanden. Auf diese Stoffe hat man zum Theil mehr Werth gelegt als auf den Gehalt an Chlor, Salpetersäure und Schwefelsäure, indem man von der Ansicht ausging, dass ihr Vorkommen die Unfähigkeit des Bodens die ihm zugeführten stickstoffhaltigen Stoffe vollständig zu oxydiren, d. h. in Salpetersäure zu verwandeln, beweise. Man nannte das "Uebersättigung des Bodens". Vergleicht man die unverhältnissmässig geringen Mengen der im Grundwasser neben der Salpetersäure enthaltenen salpetrigen Säure und des Ammoniaks, so ist schon klar, dass praktisch diese Unfähigkeit nicht viel besagen will. Ich glaube, dass der Uebertritt der genannten beiden Substanzen in das Grundwasser eher zufälligen örtlichen und zeitlichen Bedingungen entspringt; in der That ist die Constanz des Befundes häufig . sehr gering. Zu berücksichtigen ist ferner, dass salpetrige Säure wie Ammoniak ebenso gut einem nachträglicken Reductionsprocesse ihre Enstehung verdanken können, wie einer mangelhaften Oxydation. Gerade im Wasser sind derartige Vorgänge nachgewiesen.

Auf eine andere Quelle des Ammoniaks ist man erst neuerdings aufmerksam gemacht worden. Wässer, die Eisenoxydulverbindungen führen, enthalten gewöhnlich eine mehr oder weniger erhebliche Menge Ammoniak. Letzteres ist in keiner Weise verdächtig von menschlichen oder thierischen Abfallstoffen zu entstammen, sondern entsteht wahrscheinlich aus der Einwirkung von .Eisenoxydverbindungen auf vegetabilische, manchmal fossile Stoffe.

Alle zuletzt behandelten Substanzen, Chlor, Schwefelsäure, Salpeter-, salpetrige Säure und Ammoniak können auch durch directe Zuflüsse in das Wasser gelangen, nur die Salpetersäure nie in bedeutender Menge, da sie ausser im Boden nur in kleinen Mengen in Meteorwässern gelöst vorkommt. Ein bestimmtes Kriterium aber giebt uns die chemische Untersuchung allein nicht, um zu entscheiden, ob jene Stoffe direct oder auf dem Wege durch den Boden hindurch in das Wasser hineingekommen sind.

Wenn wir die übrigen im Wasser gelösten Körper als unwichtig bei Seite lassen, bleibt uns nur die Beurtheilung der organischen Substanzen. Seitdem man sich mit der vergleichenden chemischen Analyse der Wässer beschäftigt hat, spielẹn die organischen Bestandtheile derselben die Hauptrolle, obwohl man bezeichnender Weise gerade für ihre Bestimmung am wenigsten über sichere Methoden gebietet. Da diejenigen Wässer, die direct aus dem Fels entspringen, wenig, die offenen Wasser- 
läufe mehr und die Grundwässer aus den Flachbrunnen in der Nähe der menschlichen Wohnungen am meisten organische Substanzen zu enthalten pflegen, hat man sich gewöhnt, dieselben im Allgemeinen als Producte der Verwesung und Fäulniss zu betrachten. Die letzteren stehen nun aber seit den an Thieren damit angestellten Experimenten und besonders seit der Entdeckung der Fäulnissalkaloide in sehr schlechtem Geruch. Wie unbedeutend die Ausbeute an derartigen Stoffen aus faulenden Mischungen und wie verhältnissmässig gering auch deren Wirkung rom Darmcanal aus ist, wird nicht berücksichtigt.

Die Verdünnung der allenfalls gefährlichen Verbindungen durch das Wasser ist ferner eine enorme. In den schlechtesten Wässern sind pro Liter nur wenige Milligramme stickstoffhaltiger organischer Substanz enthalten. Wenn dieselbe auch bei reichlichstem und fortgesetztem Genusse üble Wirkung entfalten sollten, müsste sie zu einem guten Theil aus stärksten Giften bestehen.

Für die Flachbrunnenwässer, die in der Achtung am tiefsten stehen, weil sie am stärksten durch organische Stoffe verunreinigt sind, kommt noch der Einfluss des Bodens hinzu, der bekanntlich nicht als einfacher Filtrationsprocess, sondern als ein tiefeingreifender chemischer Vorgang aufzufassen ist. Durch denselben werden die organischen speciell stickstoffhaltigen Bestandtheile der den Boden tränkenden Abwässer fast vollständig zerstört. Wir erkennen das daran, dass bei Weitem der grösste Theil des Stickstoffs als Salpetersäure im Grundwasser erscheint. Aus einer Tabelle der Rivers Pollution Commission ${ }^{1}$ habe ich diejenigen 14 Flachbrunnenwässer, die über 15 mg Salpetersäure im Liter enthalten, ${ }^{2}$ ausgewählt und deren Gehalt an organischem und unorganischem Stickstoff verglichen. Im Durchschnitt ergiebt sich für den Stickstoff der Nitrate und Nitrite $100 \mathrm{mg}$ im Liter, für den organischen nur 1 mg. Das Verhältniss des ersteren zu dem letzteren ist also im Durchschnitt 100:1, und wenn wir den ungünstigsten Einzelfall wählen 20:1. Mindestens in demselben Maasse werden also die ursprünglich in den Abwässern vorhandenen stickstoffhaltigen Substanzen zerstört. Welch geringe Aussicht für darin enthaltene Gifte bis in's Grundwasser zu gelangen! Dass der Boden nun nicht etwa die Eigenthümlichkeit besitzt, gerade derartige Gifte unzersetzt passiren zu lassen, folgt aus den bekannten Versuchen von $\mathrm{Falk}^{3} \mathrm{Be}-$ zeichnend für die ganze Lehre ist der Umstand, dass so viel Werth

1 S. Ferdinand Fischer. Chemische Technologie des Wassers 1878. S. 93.

2 Unter Weglassung eines Brunnens, der offenbar eine ganz exceptionelle Stellung einnimmt.

${ }^{3} \mathrm{Falk}$, Vierteljahrsschrift für gerichtliche Medicin. Bd. XXXII u. XXIX. 
auf die Deduction einer schädlichen Beschaffenheit organischer Verunreinigungen des Wassers gelegt wird, aber doch kaum der Versuch gemacht wird, durch das Experiment der Sache nahezutreten. Was den chemischen Nachweis anlangt, so finde ich in der Litteratur nur die Angabe von A. Müller, ${ }^{1}$ dass der Rückstand städtischer Brunnenwässer auf Zusatz von Natronhydrat einen Seifen- und Heringsgeruch entwickelte, der auf Trimethylamin deutete. Ich selbst habe möglichst stark mit organischen Substanzen verunreinigte Brunnenwässer verschiedene Male mit Salzsäurezusatz im Vacuum bei $35^{\circ} \mathrm{C}$. eingedampft und den Rückstand nach Aufnahme in Alkohol und Wiederlösung in Wasser mit Alkaloidreagentien behandelt - ohne Erfolg. Bei dem Eindampfen einer grösseren Reihe von "schlechten" Brunnenwässern, auf die ich weiter unten noch zurückkomme, habe ich dann weiter gefunden, dass der grösste Theil der organischen Substanzen in braungefärbten, aus saurem Extract in Alkohol grösstentheils übergehenden, durch Kupfersalz fällbaren Stoffen, wahrscheinlich Huminstoffen besteht. Es scheinen gerade diese am leichtesten dem im Boden stattfindenden Oxydationsprocess zu entgehen und in das Grundwasser übertreten zu können. Ihre Herkunft kann nicht zweifelhaft sein. Unter den Abfallstoffen des menschlichen Haushaltes befinden sich regetabilische Substanzen genug, aus deren Verwesung eben Huminkörper werden; proportional der Verunreinigung steigt deren Menge im Grundwasser.

Einen grösseren Werth als die chemische Untersuchung des Wasserrückstandes hat das Experiment am lebenden Organismus. In praxi ist der Versuch ja sehr häufig gemacht worden, freilich ohne bestimmte wissenschaftliche Absicht: Zahllose Individuen geniessen stark durch organische Substanzen verunreinigtes Wasser, speciell Brunnenwasser, nicht nur einmal, sondern regelmässig, ohne die geringsten schädlichen Folgen zu verspüren. Aber auch ad hoc sind ron Emmerich ${ }^{2}$ ähnliche Experimente, und zwar theils an Thieren, theils an sich selbst angestellt worden. Durch subcutane Injection von $1 / 15-1 / 20$ ihres Körpergewichtes an Canalwasser, das durch Eindampfen concentrirt und wahrscheinlich auch von den darin enthaltenen Keimen befreit war, konnten Kaninchen in wenigen Stunden getödtet werden. Fast eine ihrem Körpergewicht gleiche Menge von Canalwasser ertrugen die Thiere aber, wenn dasselbe ihnen im Laufe ron einigen Tagen durch die Schlundsonde in den Magen eingeführt wurde. Emmerich selbst trank 14 Tage lang täglich $1 / 2$ bis

1 Zur Geschichte der Brunnenwässer grosser Städte. Journal für pralktische Chemie. Bd. LXXXII. (Citirt nach Roth u, Lex' Militairhygiene.)

${ }^{2}$ Emmerich. Zeitschrift für Biologie. Bd. XIV. S. 563. 
1 Liter stark verunreinigten Bachwassers. Obwohl beim Beginn des Versuches ein acuter Magenkatarrh bestanden hatte, wurde derselbe durch das Trinken dieses Wassers nicht verschlimmert, sondern heilte schnell. Auch andere Krankbeitssymptome traten nicht ein. Aehnlich war das Resultat bei zwei anderen Personen, die ebenfalls an Magenbeschwerden litten. Auch ein zweites Mal ertrug Emmerich selbst trotz Vorhandensein eines heftigen Magendarmkatarrhs den Genuss grösserer Mengen schlechten Bachwassers. Die subcutane Injection von $1 / 4$ bis $1 / 2$ ihres Körpergewichtes an ähnlichem Wasser, das wie oben concentrirt worden war, blieb bei Kaninchen ohne Wirkung. Ganz ebenso verhielt sich das Wasser von stark verunreinigten Brunnen, das allerdings in geringeren Mengen $(1 / 20$ bis $1 / 40$ des Körpergewichtes von frischem, $1 / 4$ bis $1 / 10$ von concentrirtem Wasser) Kaninchen unter die Haut gespritzt wurde.

Schuchny und Fodor ${ }^{1}$ kamen bei ihren ausgedehnten Versuchen zu etwas anderen Resultaten, sie benutzten ebenfalls Kaninchen, injicirten ihnen aber regelmässig 10 Procent ihrer Körpergewichtes nicht concentrirten Wassers unter die Haut. Einige dieser Thiere starben kürzere oder längere Zeit nachher, andere hatten Durchfälle und Temperaturerhöhungen.

An diesen Experimenten lässt sich manches aussetzen: Die Injectionen so riesiger Wassermengen sind offenbar für die benutzten Thiere an sich schon nicht gleichgültig; Kaninchen sind auch nicht für das Studium etwaiger künstlich verursachter Krankheitserscheinungen besonders geeignet; besonders bei jungen Thieren, wie sie vielfach Verwendung gefunden haben, bestehen schon häufig latente Krankheiten, die von einem nicht besonders darauf eingeübten Untersucher übersehen werden können (z. B. Darmcoccidiosis); ferner waren in Fodor's Versuchen etwa im Wasser vorhandene Mikroorganismen nicht ausgeschlossen. Andererseits waren die Wasserquantitäten wieder nicht so gross, um den sicheren Schluss zu gestatten, dass auch bei fortgesetztem reichlichen Genuss des betreffenden Wassers eine schädliche Wirkung auf den Organismus ausgeschlossen wäre. Es war bei einer Wiederholung solcher Experimente die Voraussetzung berechtigt, dass, wenn wirklich in einem Wasser organische Stoffe vorhanden wären, die bei einmaligem Genuss oder durch Cumulation bei lange fortgesetztem Genuss der Gesundheit nachtheilig werden könnten, dieselben durch genügend schonende Concentration des Wassers in Mengen zu gewinnen sein würden, die bei einmaliger Einverleibung auf dem wirksamsten Wege den Tod oder schwere Krankheitserscheinungen bewirkten. Für die Sterilisirung und Concentration des Wassers bot sich als schonendste Methode die Filtration

${ }^{1}$ Fodor. Archiv fiim Hygiene. Bd. III. S. 118. 
mit Hülfe des Kieselguhrfilterș und das Eindampfen im Vacuum bei $35^{\circ}$ C.; 1 Liter konnte in einem dazu geeigneten Apparat in 24 bis 48 Stunden auf den fünfzigsten bis hundertsten Theil reducirt werden. Bei der Verdünnung dieses Rückstandes mit destillirtem Wasser und Prüfung mit Kaliumpermanganat stẹllte es sich heraus, dass mindestens $2 / 3$ bis $5 / 6$ der ursprünglich im Wasser vorhandenen organischen Substanzen darin noch vorhanden waren. Der Rest ist wohl zum grössten Theil an den Wandungen des Gefässes haften geblieben. Als Weg der Einverleibung wählte ich die intraperitoneale Injection, die ja bei gelösten Stoffen fast denselben prompten Effect hat, wie die Einspritzung in's Blut. Ich experimentirte mit weissen Mäusen und Meerschweinchen. Die ersteren vertragen indifferente Flüssigkeiten, Wasser, dünne Salzlösungen, die gewöhnliche Nährbouillon in den verbältnissmässig enormen Mengen von 1 und selbst $1 \frac{1}{2}$ bis $2^{\mathrm{com}}$ sehr gut. Wenige Minuten nach dem Eingriff merkt man ihnen schon keine Krankheitserscheinungen mehr an. Erwachsene Meerschweinchen reagiren kaum auf Quantitäten ron 10 bis $20 \mathrm{~cm}$.

In der folgenden Tabelle I finden sich die Analysen der benutzten Wässer und die Ergebnisse der Experimente zusammengestellt.

Die Resultate dieser Versuchsreihe sind auf den ersten Blick überraschend: die Meerschweinchen, die den Rückstand einer Wassermenge, die dem Doppelten bis Dreifachen ihres Körpergewichtes entspricht, eingespritzt erhalten, werden dadurch nicht im geringsten in ihrem normalen Verhalten beeinträchtigt, sie erscheinen nicht einmal krank, mit einer einzigen Ausnahme, in welcher der Tod plötzlich eintritt: es betrifft dieselbe dasjenige Wasser, das durch organische Substanzen am meisten verunreinigt ist, hingegen den Salzgehalt anlangend, nicht an der Spitze der Reihe steht. Die Mäuse, die das Drei- bis Fünffache ihres Körpergewichtes in concentrirtem Wasser injicirt bekommen, reagiren schon etwas besser, 3 von 16 starben, darunter beide Mäuse, die den Rückstand des obengenannten Wassers Nr. IV erhalten; einige andere erscheinen wenigstens kürzere oder längere Zeit krank. Ohne nähere Prüfung könnten diese Ergebnisse als Beweise für die giftige Natur mancher organischer Substanzen des Wassers angesehen werden. Eine praktische Folgerung daraus zu ziehen, wäre allerdings noch nicht ohne Weiteres erlaubt, da die angewandten Mengen Wasser doch in einem zu grellen Missverhältniss gegenüber den normaler Weise consumirten Wasserquantitäten stehen. Im Gegentheil wäre der Schluss gestattet, dass letztere auch bei starker Verunreinigung in gewöhnlichen Mengen und auf dem normalen Wege, per os, eingefübrt, eine giftige Wirkung nicht entfalten würden. 
Zur hygienischen Beurtheilung des Wassers.

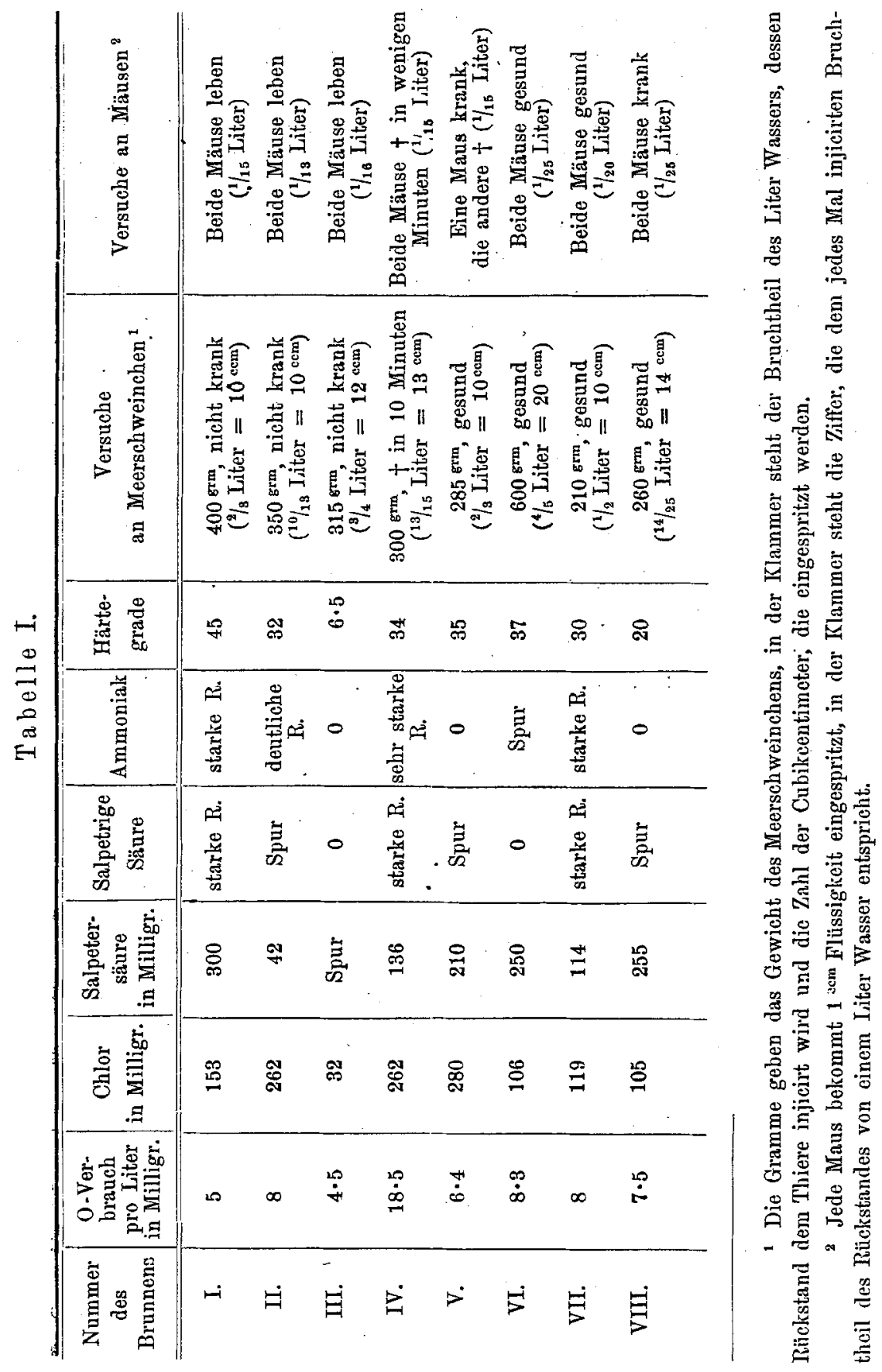


Die weitere Verfolgung unserer Experimente hat aber auch gezeigt, dass von einer Giftwirkung organischer Bestandtheile des Wassers überhaupt nicht die Rede sein kann, dass dieselbe vielmehr auf anorganische Substanzen zurückzuführen ist. In einer zweiten Versuchsreihe wurden nämlich die verdächtigen unter den genannten und einige andere Brunnenwässer nicht nur in concentrirtem Zustand eingespritzt, sondern daneben auch eingeäschert. Der von Neuem gelöste Rückstand wurde in denselben Verhältnissen Versuchsthieren injicirt. Das Resultat war für Wasser Nr. IV, das Meerschweinchen wie Mäuse getödtet hatte:

Einfach concentrirtes Wasser: 1. Maus $(1 / 10$ Liter $)+$, 2. Maus $(1 / 20$ Liter) $\dagger$, 3. Maus ( $1 / 30$ Liter) $\dagger, 4$. Maus ( $1 / 60$ Liter) bleibt leben.

Eingeäscherter und wieder gelöster Rückstand: 1 . Maus $(1 / 20$ Liter $) \dagger$, 2. Maus $(1 / 30$ Liter $) \dagger$, 3. Maus ( $1 /{ }_{00}$ Liter) bleibt leben.

Die Uebereinstimmung konnte nicht grösser sein. An der tödtlichen Wirkung mussten also anorganische Bestandtheile schuld sein.

Die Wiederholung des Versuches mit demselben Wasser ergab:

Concentrirtes Wasser: 1. Maus ( $1 / 10$ Liter) + , 2. Maus $(1 / 20$ Liter $) \dagger$, 3. Maus $(1 / 20$ Liter) krank, aber bleibt leben, 4. Maus $(1 / 40$ Liter $) \dagger$, 5. Maus $(1 / 80$ Liter) bleibt leben.

Eingeäschert: 1. Maus $(1 / 10$ Liter $) \dagger, 2$. Maus $(1 / 20$ Liter $) \dagger, 3$. Maus $(1 / 30$ Liter $)+$.

Es mag noch bemerkt werden, dass zur Erzielung möglichst gleicher Versuchsbedingungen hier wie später immer die gleiche Flüssigkeitsmenge $\left(1^{\mathrm{cem}}\right)$. eingespritzt wurde. Als Verdünnungsmittel diente destillirtes Wasser. Die Versuche verliefen im Allgemeinen recht gleichmässig, immerhin kamen doch einige Fälle ungleicher Disposition der Versuchsthiere, wie aus dem letzten Experiment ersichtlich, vor. Die verschiedene Grösse der Individuen kann das zum Theil erklären.

Mit Wasser Nr. V wurden folgende Versuche in demselben Sinne angestellt:

Concentrirtes Wasser: 1. Maus $(1 / 10$ Liter $) \dagger$, 2. Maus $(1 / 15$ Liter $)$ krank, bleibt leben, ebenso 3 . Maus $(1 / 20$ Liter $)$.

Eingeäschert: 1. Maus ( $1 / 5$ Liter $)+$, 2. Maus ( $1 / 10$ Liter) + , 3. Maus $(1 / 20$ Liter) und 4. Maus ( $1 / 40$ Liter) bleiben leben.

Für Wasser Nr. I ergab sich:

Concentrirtes Wasser: 1. Maus ( $1 / 10$ Liter) + , 2. Maus $(1 / 15$ Liter) und 3. Maus $(1 / 20$ Liter $)$ bleiben leben.

Eingeäschert: 1 . Naus ( $1 / 10$ Liter) $†$, 2. Maus ( $1 / 10$ Liter) bleibt leben, 3. Maus ( $1 / 20$ Liter) ebenfalls. 
Von Wasser Nr. VIII, das einfach concentrirt Mäuse mit 1/25 Liter krank gemacht hatte, tödtete der eingeäscherte Rückstand mit $4 / 25$ Liter.

Ein neues Wasser (IX), das $9 \mathrm{mg} 0$ pro Liter rerbrauchte, $270^{\mathrm{mg}} \mathrm{Cl}$, $700^{\mathrm{mg}} \mathrm{N}_{2} \mathrm{O}_{5}$ enthielt, starke Nitrit- und Ammoniakreactionen gab und eine Härte von $70^{\circ}$ hatte, tödtete in concentrirtem Zustand Mäuse mit $1 / 20,1 / 30$ Liter schnell, mit $1 / 40$ Liter langsam, mit $1 / 80$ Liter nicht mehr; in eingeäschertem Zustand mit $1 / 20$ und $1 / 30$, mit $1 / 40$ und $1 / 80$ nicht.

Diese Versuchsergebnisse dürften beweiskräftig genug dafür sein, dass die toxische Wirkung des Wasserrückstandes, wo sie hervortritt, auf anorganischen Bestandtheilen beruht.- Der Verdacht lenkte sich in erster Linie auf die Salze des Kaliums, dessen Giftigkeit von den hier in Betracht kommenden Metallen am grössten ist. In der That tödtete (immer wieder in $1^{\mathrm{cem}}$ Wasser gelöst)

\begin{tabular}{|c|c|c|c|c|c|}
\hline Kaliumchlorid & Mäuse & in einer & Dosis & ron & $10^{\mathrm{mg}}$, \\
\hline Kaliumnitrat & $"$ & $"$ & " & $"$ & $15-20^{\mathrm{mg}}$, \\
\hline Calciumchlorid & $"$ & $"$ & $"$ & 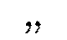 & $15^{\mathrm{mg}}$, \\
\hline Magnesiumsulfat & $"$ & $"$ & $"$ & $"$ & $25 \mathrm{mg}$, \\
\hline Natriumchlorid & ," & " & " & , & $100 \mathrm{mg}$. \\
\hline
\end{tabular}

Die Verbindungen des Calcium und Magnesium werden im Allgemeinen nicht in Betracht kommen, weil sie beim Einengen des Wassers grösstentheils ausgefällt werden, die Natriumsalze nicht, weil sie zu wenig giftig sind, es bleibt also nur das Kalium zur Erklärung jener Wirkungen. ${ }^{1}$ Dass es in den nöthigen Mengen im Wasser vorhanden sein kann, erhellt aus früheren Analysen, dass es wirklich in unserem Falle die entscheidende Rolle spielte, ergab seine directe Bestimmung.

Im Wasser Nr. IV fanden sich $296 \mathrm{mg}$ Kaliumchlorid im Liter, wenn wir das vorhandene Metall an Chlor gebunden denken. Der Räckstand von $1 / 30$ Liter, der noch Mäuse tödtete, enthielt also etwa $10^{\mathrm{mgr}} \mathrm{KCl}$, gerade die tödtliche Dosis des Kaliumchlorids!

Ein ähnliches Resultat gab die Analyse des Wassers Nr. IX;

$\mathrm{KCl}=267 \mathrm{mg}$ im Liter. Auch hier tödtete $1 / 30$ Liter des Rückstandes noch.

Fs kann also wohl keinem Zweifel unterliegen, dass wir in den wenigen Experimenten, in denen die Einverleibung des Wasserrückstandes in Versuchsthieren einen kräftigen Effect geübt hat, es mit Kaliumwirkungen zu thuu gehabt haben. Die organischen Stoffe stehen dem-

${ }^{1}$ Die salpetrige Säure kommt nicht in Betracht, denn, wie Controlexperimente beweisen, beginnt die tödtliche Wirkung derselben auf dem intraperitonealen Wege erst $z$ wischen Dosen von $\mathbf{2 \cdot 5}$ bis $5^{\mathrm{mg}}$ Nitrit. Solche Mengen waren in keinem der eingespritzten Wässer vorhanden. 
nach, was giftige Wirkung im Wasser anbelangt, hinter den anorganischen Salzen zurück. Von den letzteren giebt aber Jedermann in praxi ihre völlige Unschädlichkeit zu. Bleibt da für die organischen Substanzen noch etwas übrig?

In Ermangelung positiver Beweise für einen directen Einfluss der organischen Bestandtheile des Wassers hat man ihnen eine indirecte, die Disposition zu Infectionskrankheiten steigernde Wirkung zu= schreiben wollen. Den Gegenbeweis zu liefern, wie es uns bei dem vorangehenden Punkte möglich war, sind wir natürlich nicht im Stande, sondern müssen uns in diesem Falle damit begnügen, auf den Mangel jedes thatsächlichen Fundamentes für diese Behauptung hinzuweisen. Wenn es rorkommen mag, dass in einer grösseren Stadt gerade diejenigen Bezirke; die auf herrorragend verunreinigtes Brunnenwasser angewiesen sind, von einer Epidemie besonders heftig befallen werden, so ist deswegen noch nicht der Schluss exlaubt, dass die Verunreinigung durch organische oder gelöste Stoffe überhaupt als wesentlicher ätiologischer Factor dabei eine Rolle spielt, ganz andere Momente können da in Betracht kommen: Diese Stadttheile pflegen sich auch in rielen anderen Beziehungen, z. B. in geringer Reinlichkeit der Häuser, grösserer Dichtigkeit und geringerem Wohlstand der Bevölkerung vor den übrigen auszuzeichnen. In vielen anderen Fällen ist auch nachweislich die Disposition zu infectiösen Erkrankungen durchaus nicht an die Stadttheile gebunden, deren Grundwasser besonders verunreinigt ist (Flügge).

Man kann ebensowenig wie einen stärkeren Gehalt an anorganischen Bestandtheilen der "Stadtlauge" einen solchen an organischen als Indicator einer möglichen Verseuchung mit Infectionsstoffen betrachten, da ja auch die organischen Substanzen durchaus nicht einer directen Verunreinigung des Wassers ihren Ursprung zu verdanken pflegen, sondern dem Filtrationsprocess in einem von der Oberfläche aus mit Schmutzstoffen getränkten Boden. Dass die organischen Gifte dabei nicht den Weg in's Wasser finden, haben wir oben gesehen, dass es den organisirten Elementen der Abwässer, etwaigen Infectionserregern selbst nicht besser geht, werden wir weiter unten erörtern. Die Erfahrung lehrt dementsprechend, dass Krankheitskeime ebensowohl in Wässern mit verhältnissmässig geringem Gehalt an organischen Bestandtheilen, als in solchen mit hohem vorkommen. Der Grund davon ist, dass die infectiōsen Agentien nur durch directe Zuflüsse in das Wasser hineingelangen, Zuflüsse, die die chemische Qualität des Wassers nicht sichtlich zu beeinflussen brauchen. Man kann sich leicht eine Vorstellung daron machen, wenn man bedenkt, dass wenige Tropfen einer Choleradejection genügen, um jeden Cubikcentimeter eines Brunneninhaltes mit einer stattlichen Anzahl 
von Kommabacillen zu bevölkern, während die dadurch entstehende chemische Verunreinigung doch nicht nachweisbar ist.

Als letzter Ausweg, den organischen Substanzen des Wassers eine gewisse Bedeutung zu retten, böte sich der, dass man sie als Nährstoffe für infectiöse Mikroorganismen hinzustellen suchte. Ob diese Ansicht experimentell zu begründen ist, wird sich später ergeben, a priori ist von dem auch im schlechtesten Wasser noch minimalen Gehalt an organischen Stoffen gerade keine grosse Wirkung zu erwarten. Gegenüber der Thatsache, dass überhaupt Krankheitserreger in ein Wasser hineingelangt sind, hat die Möglichkeit, dass sie sich innerhalb desselben in geringem Maasse vervielfältigen können, kaum Bedeutung.

Das Facit unserer Untersuchung über den Werth der ehemischen Methode für die hygienische Beurtheilung des Wassers ist sonach ein sehr ungünstiges, wenn wir die Bedeutung der einzelnen Bestandtheile kritisch zu würdigen suchen. Es fragț sich, ob sich unser Urtheil ändert, wenn wir das Gesammtresultat der chemischen Prüfung in Rechnung ziehen. Man pflegt auf Grund derselben ein Wasser rein oder stark verunreinigt, gut oder schlecht zu nennen. Kann man daraus etwa praktische Consequenzen ziehen? Manche, die eigentliche Gründe für ihr verwerfendes Urtheil nicht anzugeben vermögen, nehmen ihre Zuflucht zu unbestimmten Gefühlen, dem Gefühl des Ekels, das sie bei der Vorstellung, aus welchen unedlen Bestandtheilen die das Grundwasser zusammensetzenden Stoffe hervorgegangen seien; empfinden. Wie aus dem zweiten Abschnitt dieser Arbeit hervorgeht, lege auch ich auf die Appetitlichkeit des Trinkwassers einen nicht geringen Werth, aber doch nur soweit dieselbe auf wirklichen physiologisch hervortretenden Eigenschaften desselben beruht; ob sie von charakteristischen chemischen Kennzeichen begleitet sind oder nicht, bleibt dabei gleichgültig. ILassen wir auch die Einbildung mitsprechen, so geht jeder Maassstab für eine objective Beurtheilung verloren. Von meinem Standpunkt aus würde ich jedenfalls das "schlechteste" Brunnenwasser, wenn es die sinne nicht beleidigt und unverdächtig ist, jedem noch so gut filtrirten Flusswasser vorziehen.

Eine andere Art der Beweisführung, nämlich die statistische, haben wir schon bei der Beurtheilung der organischen Substanzen zurückgewiesen. Wenn man, angeblich auf Grund ziffernmässigen Nachweises, die „unreine" Beschaffenheit des Trinkwassers nicht nur als Ursache grösserer Häufigkeit von Infectionskrankheiten, sondern auch einer höheren allgemeinen Sterblichkeit anschuldigt, so übersieht man die Complicirtheit der neben dem Einfluss des Wassers in Betracht kommenden Momente. 
IV.

Die vierte Beurtheilungsmethode des Wassers haben wir die mikroskopische genannt, weil sie auf der Lehre beruht, dass mikroskopische Elemente, und zwar solche organisirter Natur, gesundheitsschädliche Wirkungen auszuüben im Stande seien. Die Begründung dieser ursprünglich nur auf epidemiologischen Thatsachen beruhenden Theorie ist durch die Entwickelung der Bakteriologie wesentlich gestützt worden, indem die letztere uns gelehrt hat, die Infectionsmöglichkeiten sicherer zu beurtheilen und manchmal sogar die Infectionserreger selbst im verdächtigen Wasser abzufangen. Dass Erkrankungen durch Vermittelung des Wassers übertragen werden und dass die präsumtiven Krankheitskeime durch directe Zuflüsse in dasselbe hineingelangen können, haben unbefangene Beobachtungen schon vor Entdeckung der specifischen Mikroorganismen ausserordentlich wahrscheinlich gemacht; so hat man denn schon früher offene Wasserläufe, schlecht gefasste Brunnen und Quellen für infectionsverdächtig erklärt. Praktische Erfahrungen über die Wirkung der natürlichen und künstlichen Filtration schienen ferner für die Möglichkeit, gefährliche Wässer unschädlich zu machen, zu sprechen. Erst durch die bakteriologischen Methoden sind wir aber in den Stand gesetzt worden, präcise Regeln für die Entnahme eines unverdächtigen und für die Reinigung eines verdächtigen Wassers aufzustellen.

Die ,jungfräuliche" Beschaffenheit der aus dem Fels entspringenden Quellen ist auch durch die Bakteriologie nicht angetastet worden, eine sehr bedeutende Concurrenz ist aber jetzt denselben - durch das Verdienst der Bakteriologie - in den Grundwäss ern erstanden. Wohl bemerkt beruht die jungfräuliche Natur der letzteren einzig und allein auf ihrer Reinheit von Infectionsstoffen, nicht auf chemischer Reinheit. Es kann als bewiesen betrachtet werden, dass auch ein stark verunreinigter Boden der Regel nach ein keimfreies Grundwasser hat. Der erste bakteriologische Beweis dafür wurde durch R. Koch ${ }^{1}$ in der Thatsache gefunden, dass die Zahl der im Boden enthaltenen Bakterien von der Oberfläche nach der Tiefe zu rapid abnimmt. Die Boden- und Wasseruntersuchungen von C. Frănkel, ${ }^{2}$ Reimers, ${ }^{3}$ Fülles, ${ }^{4}$ Proskauer, ${ }^{5}$ Flügge u. A. bestätigten und präcisirten jenes Ergebniss dahin, dass in einer gewissen Tiefe überhaupt keine oder sehr spärliche Mikroorganismen sich finden. Die Erklärung für diese Thatsache liegt wohl erstens in

${ }^{1}$ R. Koch. Mittheilungen aus dem Reichsgesundheitsamt. Bd. I. S. 35.

2 C. Fränkel. Diese Zeitschrift. Bd. II. S. 521. - Bd. VI. S. 23.

3 Reimers. Ebenda. Bd. VII. S. 307.

4 Fülles. Ebenda. Bd. X. S. 225.

"Proskauer. Ebenda. Bd. XI. S. 3. 
dem Filtrationsvermögen des Bodens und zweitens in den physikalischen Verhältnissen in der Tiefe desselben. Daraus allein schon ergeben sich einige natürliche Beschränkungen des oben ausgesprochenen Lehrsatzes. Wo der Boden so grobporig ist, dass eine eigentliche Filtration nicht stattfindet und wo andererseits das Grundwasser bis in diejenigen Erdschichten hinaufreicht, die noch ein Mikroorganismenwachsthum zeitigen, da gehen auch Bakterien in das Grundwasser über. Ob sich darunter auch pathogene Agentien befinden können, wird von den sonstigen localen Verhältnissen abhängen. Praktisch liegen die genannten Ausnahmen vor ¿. B. in Dorpat, dessen Grundwasser schon im Allgemeinen in geringer Tiefe unter der Bodenoberfläche beginnt und dementsprechend überall sehr reich ist an Bakterien, ${ }^{1}$ und bei Jena, wo von Reimers bei $1.9^{\mathrm{m}}$ Tiefe bakterienhaltiges Grundwasser gefunden wurde.

Bei der Frage, ob ein Grundwasser der Forderung, dass es sicher frei von Infectionskeimen sei, genügt, kommt also in erster Linie die Güte und Stärke der filtrirenden Schicht in Betracht, über dieselbe wird im einzelnen Falle nicht allzu schwer zu entscheiden sein. Am sichersten ist die Prüfung.durch das Experiment: man entnimmt unter den nöthigen Cautelen Proben des Grundwassers und analysirt dieselben bakteriologisch. Wir kommen damit zu der Frage, die praktisch die allergrösseste Bedeutung hat, zu derjenigen nach der MLthode der Entnahme des Grundwassers. Soll die Benutzung des an sich auch unverdächtigen Grundwassers gefahrlos sein, wie hat man dieselbe einzurichten, mit anderen Worten, wie hat man eine nachträgliche Infection des Brunnenwassers von aussen her zu verhüten? Am sichersten ist die Entnahme des Wassers durch Rohrbrunnen - für das oben geforderte Experiment ist dies die einzig zulässige Methode. Praktisch genügt dem Bedarf ein einzelner Rohrbrunnen oft nicht, einerseits weil der Wasserbedarf zu gross ist, andererseits weil die Entnahme möglichst sich an schon vorhandene Einrichtungen anschliessen soll. Dem grossen Bedarf kann man allenfalls durch Combination mehrerer Rohrbrunnen genügen, immerhin ist für manche Zwecke (z. B. des Feuerlöschwesens) die Anlage von Kesselbrunnen doch nicht zu umgehen. Wir müssen aber in praxi namentlich noch mit diesen rechnen, weil sie eben einmal bestehen. Es unterliegt keinem Zweifel, dass sehr viele dieser Anlagen durchaus umhygienische sind. Häufig sind die Wege, auf denen schädliche Zuflüsse in das Brunnenwasser gelangen können, auf den ersten Blick zu erkennen. Andere Male sind unter einem unverdächtigen

1 Tager, Bakteriologische Untersuchungen des Grundwassers in Jurjew. Diss. Dorpat 1893. 
äusseren Ansehen innere Schäden verborgen, man sollte sich darum, wenn möglich, nie mit einer äusseren Besichtigung begnügen, sondern stets einen Einblick in den Brunnenschacht selbst zu gewinnen suchen. Oft findet man dort in Rinnsalen, die an der Kesselwand entlang laufen, ganz unverkennbare Spuren von Zuflüssen, die äusserlich nicht sichtbar waren. Schliesslich giebt es Brunnen, die in ihrer Anlage von aussen wie innen ohne Fehl zu sein scheinen, bei denen man aber aus der Berücksichtigung örtlicher Verhältnisse, z. B. der allzu grossen Nähe von Abortgruben, auf einen bestimmten Verdacht hingewiesen wird. Auch für Schachtbrunnen bestehen genügende Möglichkeiten vorwurfsfreier Anlagen. Wenn man bedenkt, dass es namentlich die Ausflussstelle des Wassers ist, wo schmutzige Wäsche eingeweicht, unreine Gefässe gespült werden, dass fêrner die Abflussstelle (Ausguss, Schlammfang) allen möglichen Unrath aufzunehmen hat, so ist die Forderung gerechtfertigt, dass beide Stellen entfernt von dem Schacht selbst liegen. Sebr leicht ist das durch Einschaltung eines Kniestückes in das Saugrohr zu ermöglichen. Je weiter die Pumpe vom Brunnen entfernt liegt, desto leichter wird eine specifische Verunreinigung vermieden. Manchmal schliesst schon die Lage des eigentlichen Brunnens an einem abseits liegenden Punkt, z. B. im Garten, in einem abgeschlossenen Kellerraum, die Infectionsgefahr aus, obwohl die Verfassung des Schachtes selbst viel zu wünschen übrig lässt. Bei unmittelbarer Stellung der Pumpe über dem Kessel sind Verunreinigungen derselben durch gute Fassung zu verhindern: dazu gehört vor allen Dingen Abdichtung der Abflussrinne für das Wasser oder, wenn der Ausguss dicht dabei liegt, des letzteren; der Rand des Brunnens ist zweckmässig erhöht und cementirt. Auf die völlig dichte Bedeckung des Schachtes ist in diesem letzteren Fall nicht allzu grosses Gewicht zu legen, um aber sicher zu gehen, bringt man am besten ein schräges, wasserdichtes Dach über demselben an. Manche Brunnen tragen eine Cementbekleidung nicht nur an dem den. Frdboden überragenden Rande, sondern auch noch tief unter der Oberfläche. Wo das nicht geschieht, ist möglichst für eine undurchdringliche Schicht um den Brunnen herum Sorge zu tragen, sei es, dass man die Umgebung gut pflastert, asphaltirt oder cementirt. Auch eine unter der Pfasterung liegende Lehmschicht, die bis zu einer gewissen Tiefe den gemauerten Schacht umgiebt, ist zu empfehlen. Bei allen Vorrichtungen, die zur Abdichtung dienen, ist zu bedenken, dass sie von Zeit zu Zeit der Reparatur bedürfen; ganz besonders gilt dies für den Ausguss vor dem Brunnen. Durch die Beachtung dieser Verhältnisse kann man auch die Kesselbrunnen zu rorwurfsfreien Anlagen machen. R. Koch hat neuerdings vorgeschlagen, die Gefahr einer Verunreinigung des, Kessels dadurch zu umgehen, dass 
man denselben etwa in einer Tiefe von $2^{m}$ mit einer Decke versieht und darauf eine Sandschicht bringt, die bis zur Oberfläche reichen muss. In ähnlicher Weise hat man die Schachte auch schon früher, wenn auch meist aus anderen Gründen, unsichtbar angelegt; die überdeckende Schicht pflegte dann nicht so stark und manchmal recht durchlässig zu sein, so dass die filtrirende Wirkung sehr mangelhaft ausfallen musste. Koch giebt in seiner letzten Publication ${ }^{1}$ ein Beispiel dafür in einem Altonaer Brunnen.

Bei allen Grundwasser-Brunnenanlagen ist $\mathrm{zu}$ bedenken, dass die Bodenfiltration nur dann ein unverdächtiges Wasser liefert, wenn die Erdpartikelchen allenthalben durch capillare Räume mit einander verbunden sind. Spalten, Risse, Löcher im Erdreich stellen Wege vor, die für corpusculäre Elemente und also auch für infectiöse Mikroorganismen passirbar sind. Bei Kesselbrunnen ist die Möglichkeit solcher mehr oder weniger directer Verbindungen der Oberfläche mit dem Grundwasser bedeutend grösser als bei Rohrbrunnen, ist aber auch bei mangelhafter Einrichtung und Instandhaltung der letzteren vorhanden. Ein besonderes Interesse verdienen gänzlich unterirdische Communicationen, die man vielfach zwischen beieinander gelegenen Brunnenkesseln und Senkgruben angenommen hat. Dass dieselben vorkommen, will ich nicht mit absoluter Sicherheit ableugnen, Beweise dafür sind aber auch noch nicht erbracht. Im höchsten Grade unwahrscheinlich erscheint ein Zusammenhang zwischen vielen Metern weit von einander entfernten Brunnen und Grubenanlagen, den man sich gewissen epidemiologischen Erfahrungen zu Liebe construirt hat. Viel näher liegt es meines Erachtens, den Weg für die Infection an der Oberfläche selbst zu suchen. Der Möglichkeiten giebt es ja da genug. Trotzdem will ich damit die Nähe einer Senkgrube nicht als gänzlich belanglos für einen Brunnen hinstellen. Meist wird die chemische Zusammensetzung des Grundwassers durch die in reichlichsten Mengen in der Tiefe des Bodens angehäuften Abfallstoffe beeinflusst, oft genug in der Weise, dass auch die Appetitlichkeit desselben entschieden darunter leidet. Man darf eben nicht vergessen, dass der Boden, dessen filtrirende Kraft völlig ausreicht, corpusculäre Elemente zurückzuhalten, in dem Absorptionsvermögen für Gase und gelöste Stoffe beschränkt ist.

Wenn Quell- und Grundwasser im Allgemeinen, vom bakteriologischen Standpunkt betrachtet, als jungfräuliche Wässer gelten können, so ist das Gegentheil bei allen 0 berflächenwässern der Fall, seien es nun Meteoroder See-, Bach- und Flusswässer. Sie gegen das Zutreten von Mikro-

${ }^{1}$ R. Koch. Diese Zeitschrift. Bd. XV. S. 116. 
organismen überhaupt zu schützen, erscheint unmöglich, ein erreichbares Ziel, das der Hygiene vorschweben muss, ist es aber, auch diese Wässer vor der Vermischung mit infectiösen Agentien $z u$ bewahren. Verhältnissmässig einfach ist die Aufgabe bei den Meteorwässern, die, in Cisternen aufgefangen, zum Gebrauch des Menschen dienen, zu lösen, wenn auch gerade in den Ländern, die auf diese Art der Wasserversorgung angewiesen sind, bisher wenig in diesem Sinne gethan ist. Sehr viel schwieriger ist es, die offenen Wasserläufe und -Becken von infectiösen Verunreinigungen frei zu halten, da es dabei gilt, den Kampf mit zahllosen alten Rechten und Gewohnheiten aufzunehmen. Der Staat hat in neuerer und neuester Zeit diesen Kampf begonnen. Erschwert wird derselbe erheblich dadurch, dass über einige in Betracht kommende Fragen noch nicht die wünschenswerthe wissenschaftliche Uebereinstimmung erzielt worden ist. . Die Selbstreinigung der Flüsse ist ein Capitel dieser Art. Dass es eine solche giebt, ist nicht zu bezweifeln, worauf sie aber beruht und namentlich welche praktische Grenzen sie hat, das steht noch zur Discussion. Einige Beiträge dazu wird man im Folgenden finden. Die specifische Verunreinigung der offenen Gewässer kann auf zweierlei Wegen erfolgen, entweder dadurch, dass die anliegenden Ortschaften ibre Abfallstoffe in das Wasser hineingehen lassen - die Wirkung der Verunreinigung erstreckt sich dann naturgemäss nur stromabwärts - oder durch den Schiffswerkehr, der auch stromaufwärts besteht. Die Geschichte der Cholera in den letzten zwei Jahren hat gerade auf diese letztere Gefahr wieder aufmerksam gemacht und dem entsprachen die in hygienischem Interesse ergriffenen Vorsichtsmassregeln: die Einrichtung von Stationen zur Ueberwachung des Verkehrs auf den Hauptströmen. Es handelt sich hier um Ausnahmemassregeln, man hätte aber, so. lange die Flusswasserversorgung noch in solcher Ausdehnung verbreitet ist, die Möglichkeit zu erwägen, ob nicht an gewissen gefährlichen Punkten diese Stationen zu dauernden gemacht werden sollten. Die Cholera ist nur ein vorübergehender, der Tðphus ein ständiger Gast unserer grossen Städte. Ein Theil der Erkrankungen an letzterem dürfte wohl, auch wenn grössere Epidemieen fehlen, auf die Wasserleitung zurückzuführen sein.

Fast ebenso wichtig wie die Frage nach der richtigen Methode der Wasserentnahme ist diejenige nach der Behandlung verdächtiger Wässer behufs ihrer Reinigung von Infectionsstoffen. In letzter Linie ist es Sache des Consumenten selbst, sich zu schützen, sei es durch Abkochen des Wassers, sei es durch richtige Benutzung ron Hausfiltern, in erster Iinie hat aber derjenige, der das Wasser liefert, der Staat, die Gemeinde, der Brunnenbesitzer die Pflicht, für die Ausschaltung aller Verdachtsmomente zu sorgen. 
Wo es sich nur um einzelne Brunnen handelt, ist die Hülfe ziemlich einfach. Man kann an eine eigentliche Desinfection der Anlage denken. Sehr geringe Mühe und Kosten macht dieselbe bei Rohrbrunnen: nach C. Fränkel genügt es, einige Liter roher Carbolsäure und Schwefelsäure zu gleichen Theilen gemischt in das Rohr einzugiessen, den Brunnen 24 Stunden sich selbst zu überlassen und dann abzupumpen, bis jede Spur des Desinfectionsmittels entfernt ist. Aber wann wird je die Nothwendigkeit eintreten, einen Rohrbrunnen von Krankheitskeimen zu befreien? Praktisch allein kommt der Fall einer Verseuchung von Kesselbrunnen in Betracht. Nach demselben Autor gelingt es nur unvollständig, die Desinfection bei letzteren zu bewirken, der am Boden lagernde Schlamm hindert die gleichmässige Verbreitung der Desinfectionsmittel in dem wasserführenden Theil des Schachtes. Indessen lässt sich dieser Schlamm mechanisch entfernen, die nachfolgende Behandlung mit roher Carbolsäure, Schwefelsäure oder besser Aetzkalk dürfte danach wohl zum Ziele führen. Um so mehr, als es ja kaum beabsichtigt wird, die völlige Abtödtung alles organischen Lebens, auch der widerstandsfähigsten Sporen, zu erreichen, sondern nur die Befreiung von ganz bestimmten, viel weniger' resistenten Krankheitskeimen. Unumgänglich nothwendig ist es aber auch, den über dem Wasser liegenden Theil des Kessels zu desinficiren und hierin wird oft die grösste Schwierigkeit liegen. Denn die inficirenden Stoffe werden nur in einem Theil der Fälle direct vom oberen Rande des Brunnens aus ihren Weg in den Schacht himein finden, häufig geschieht das durch mehr verborgene seitliche Zuflüsse. In diesem Falle ist ein radikaleres Vorgehen geboten. Der ganze obere Theil des Kessels muss ron aussen durch Cementirung undurchlässig gemacht und von innen durch Kalkanstrich desinficirt werden; der Brunnenrand und seine Umgebung ist nach den oben gegebenen Vorschriften dicht zu construiren. Früher half man sich dadurch, dass man den Brunnen auf einige Zeit oder dauernd schloss. Am sichersten geht man natürlich mit der letzteren Massregel, die erstere ist ungenügend.

Sind centrale Wasserversorgungen rerseucht, so kann das entweder seinen Grund in Verunreinigungen haben, die durch Defecte in den Leitungen oder durch schadhafte Stellen in der Fassung der Quellen eintreten oder aber in inficirter Beschaffenheit des zum Gebrauch dienenden Wassers selbst. Diese letzte Möglichkeit interessirt uns hier vor Allem. Sie wird im Allgemeinen nur bei Versorgungen, die aus offenen Wasserläufen oder -Becken schöpfen, eintreten. Bestehen keine Einrichtungen zur Filtration, so ist das einzige Mittel gegenüber der Verseuchung völliger Schluss der Wasserleitung bis zu dem Zeitpunkt, in dem das offene Wasser wieder unverdächtig geworden ist. Giebt es eine centrale Filtration, so 
ist diese mit der grössten Gewissenhaftigkeit nach den Normen, die im letzten Sommer vom Reichsgesundheitsamt veröffentlicht und in einer Publication von Koch erläutert worden sind, zu überwachen. Soweit man nach den bisherigen Erfahrungen urtheilen kann, wird in der That durch einen sorgfältigen Filterbetrieb die wesentliche Infectionsgefahr durch das Wasser beseitigt. Möglich wäre es freilich, dass trotz genanester Beobachtung genannter Vorsichtsmassregeln dennoch die Verseuchung des Wassers fortbestände, in dem Fall nämlich, dass sich in den Filtern locale Wucherungsherde der Infectionserreger ausgebildet hätten. Beobachtet ist, wie gesagt, dieser Fall noch nicht, aber sehr wohl denkbar. Der Abhülfe würden erheblichere Schwierigkeiten entgegenstehen, da man dann entweder an gänzliche Erneuerung der Filter oder an ihre Desinfection im Grossen $\mathrm{zu}^{1}$ denken hätte.

Bei Verseuchung centraler Wasserversorgungen ist im Allgemeinen die Nothwendigkeit, auch das ganze Leitungsnetz zu desinficiren, nicht vorhanden, wo allerdings die Einrichtung von Hausreservoiren besteht, kann aus deren Vernachlässigung eine ernste Gefahr entstehen. Hier ist die örtliche Desinfection entschieden am Platze.

Wir gelangen jetzt zu der Betrachtung der im Wasser vorkommenden organisirten Krankheitserreger im Einzelnen und haben uns dabei auch über den Werth zu äussern, den der Befund von nicht pathogenen Organismen im Wasser für die Beurtheilung des letzteren hat. Wir können hier drei Arten mikroskopischer Organismen unterscheiden: Bakterien, Protozoën und Würmer oder deren Keime.

Im Vordergrunde des Interesses steht augenblicklich der Bacillus der asiatischen Cholera. Es ist überflüssig, hier noch einmal alle Thatsachen zusammenzutragen, die die Jebertragbarkeit dieser Seuche durch das Wasser beweisen. ${ }^{2}$ Auch die Gegner dieser Theorie geben nach der Epidemie des Jahres $1892 \mathrm{zu}$, dass das Wasser, und zwar in grössestem Maassstabe, die Verbreitung der Infection vermitteln kann. Für unbefangene Beurtheiler liegt es, da jeder Beweis fehlt, dass Zwischenglieder zwischen dem Wasser und dem Munde des Menschen vorhanden sein müssen, am nächsten, anzunehmen, dass die Infection sich häufig auf diesem Wege vollzieht. Dass in anderen Fällen solche Zwischenglieder existiren können, braucht deswegen nicht geleugnet zu werden. Vor der letzten grossen Epidemie hat es nur in wenigen Fällen gelingen

1 Vielleicht wäre dazu die Schwefelsäure (vgl. diese Zeitschrift Bd. XV, S. 86), kaum dagegen wegen der jm Sandfilter reichlich vorhandenen organischen Substanz der Chlorkalk (diese Zeitschrift Bd. XVI, S. 149) geeignet.

${ }^{2}$ Vgl. C. Flügge, Die Verbreitungsweise nnd Verhütung der Cholera u. s. w. Diese Zeitschrift. Bd. XIV. Hft. 1. 
wollen (R. Koch, Nicati und Rietsch, Pasquale), den directen Nachweis des Cholerabacillus in dem inficirenden Wasser zu führen, die Zahl der Beispiele dafür ist im Laufe des letzten Jahres erheblich gewachsen (C. Fränkel, Lubarsch, Wallichs, Koch, Spronck, Mendoza u. A.). Dem erwähnten Mangel versuchte man früher auf experimentellem Wege zu begegnen, indem man den Cholerabacillus in's Wasser übertrug und sein Verhalten in demselben studirte. Dabei zeigte es sich nun in einer ersten Reihe von Experimenten, dass unser Bacterium, in sterilisirte natürliche Wässer eingesät, sich lange, d. h. Wochen und Monate in demselben hielt, ja sogar in einigen Fällen sich vermehren konnte (Bolton, ${ }^{1}$ Wolffh ügel und Riedel ${ }^{2}$ ). Durch eine neue Versuchsreihe, in welcher nicht sterilisirtes Wasser verwendet wurde, suchte demgegenüber Kraus ${ }^{3}$ zu beweisen, dass die Concurrenz der Wasserbakterien dem Cholerabacillus nur ein kurzes, höchstens auf ein bis zwei Tage beschränktes Dasein im Wasser gestattete. Aehnlich fielen die Experimente von Karlinski aus. Dieses Resultat wurde von den Gegnern der Wassertheorie weidlich benutzt, um ihre Anschauung zu vertheidigen. Als ein Fortschritt war es daher zu betrachten, dass Pasquale ${ }^{5}$ in einem Brunnenwasser von Massaua mit Hülfe der Schottelius'schen Methode noch neun Tage nach der Entnahme Cholerabacillen nachweisen konnte. Im letzten Jahre gelang dasselbe nach Koch's Bericht in einem Altonaer Brunnenwasser, das bei 3 bis $5^{0}$ conservirt wurde, noch nach 18 Tagen. Dieser Sachverhalt liess eine erneute systematische Prüfung der Frage nach der Haltbarkeit des Cholerabacillus in Wässern verschiedener Herkunft und $\mathrm{Zu}$ sammensetzung wünschenswerth erscheinen. Ich konnte mit um so mehr Aussicht auf Erfolg daran gehen, weil die Schottelius'sche Methode in letzter Zeit durch Anwendung von Peptonkochsalzlösungen eine entschiedene Verbesserung erfahren hat.

Im Ganzen wurden 20 Wässer (s. Tab. II) zum Versuche verwandt. Nr. 1 bis 18 sind Brunnenwässer aus Breslau, Nr. 19 filtrirtes Oderwasser aus der neuen Wasserleitung, Nr. 20 unfiltrirtes Oderwasser aus der alten Leitung. Die Tabelle II giebt ein Bild von der ausserordentlich verschiedenen Beschaffenheit dieser Wasserproben. Das Experiment wurde in Bierflaschen, die einen halben Liter fassen konnten und mit $400^{\mathrm{ccm}}$ gefüllt wurden, angestellt. Die Einsaat betrug 11 bis 15 Millionen Bacillen,

1 Bolton. Diese Zeitschrift. Bd. I. S. 76.

${ }^{2}$ Wolffhügel d. Riedel. Arbeiten des Reichsgesundheitsamtes. Bd. I. S. 461.

${ }^{3}$ Kraus. Archiv für Hygiene. Bd. VI. S. 234.

4 Karlinski. Ebenda. Bd. IX. S. 113.

${ }^{5}$ Pasquale, Il colera a Massaua. Gionnale medico del $R$. Exercito e della R. Marina. 1891 . 


\begin{tabular}{|c|c|c|}
\hline  & $\overrightarrow{0} \infty \infty \sim \sigma$ or $A \infty N-$ & 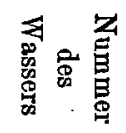 \\
\hline 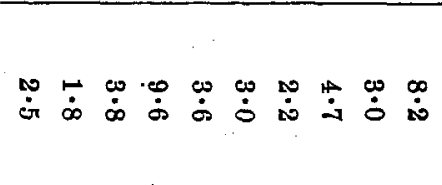 & 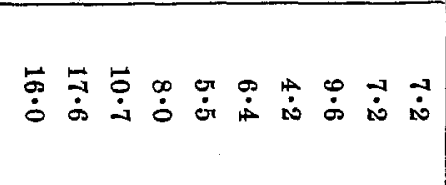 & 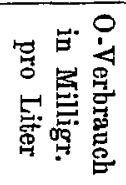 \\
\hline  & 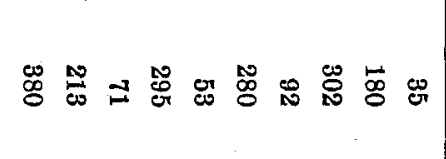 & 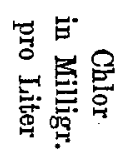 \\
\hline$=$ 营 & 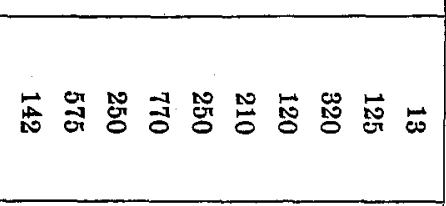 & 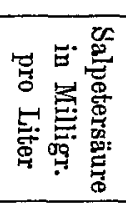 \\
\hline 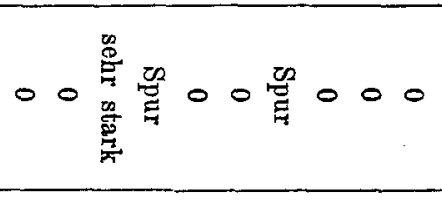 & 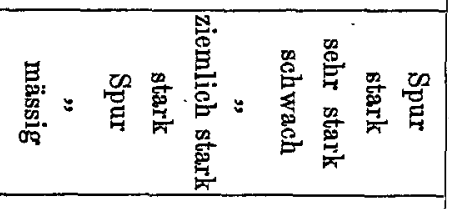 & 㟒莺 \\
\hline 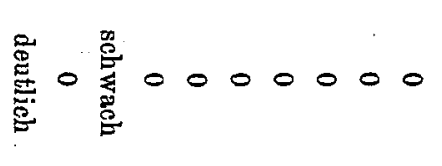 & 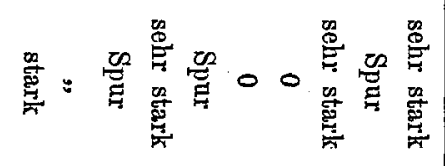 & 苞 \\
\hline 际 & 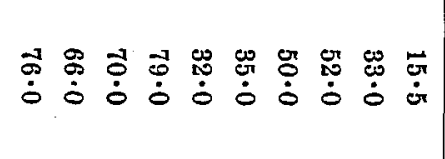 & 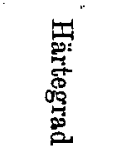 \\
\hline 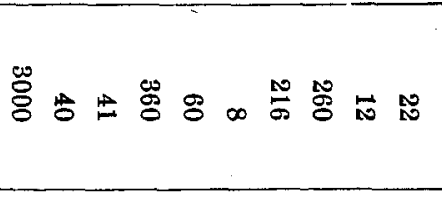 & 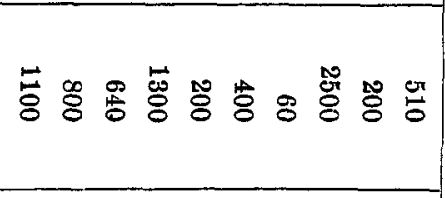 & 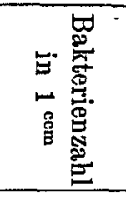 \\
\hline 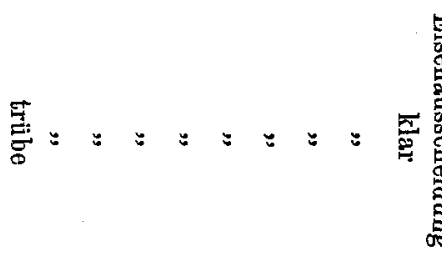 & : =: =: = & 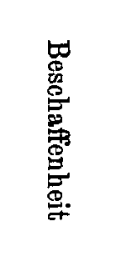 \\
\hline
\end{tabular}


etwa der 200. Theil einer im Wasser aufgeschwemmten 18 stündigen Agarcultur des Cholerabacillus, die von einem im Januar 1893 vorgekommenen Hamburger Falle stammte, also etwa ein halbes Jahr lang auf künstlichem Nährboden cultivirt war. Es wurde Werth darauf gelegt, die Emulsion möglichst frei von gröberen Partikelchen herzustellen. Die Wässer wurden vor Licht geschützt, bei der nahezu constanten Temperatur von $16^{\circ}$ gehalten. Die Resultate waren folgende: Mit Ausnahme eines einzigen Wassers (Nr. 16) liessen sich noch nach einer Woche in den nach sorgfältigem Umschütteln zur Untersuchung kommenden $100^{\mathrm{cem}}$ aller Proben Cholerabacillen nachweisen. Nach zwei Wochen waren die letzteren unter gleichen Bedingungen noch bei neun Wässern, also fast in der Hälfte der Fälle, vorhanden (Nr. 1-6, 9, 10, 18), nach vier Wochen noch in drei Wässern (Nr. 4, 6, 10). Eine Wiederholung des Experimentes für zwei derselben Wässer (Nr. 4 und 20), aber bei anderen Temperaturen, nämlich sowohl bei $8^{\circ}$ als bei $22^{\circ}$, ergab wieder nach einer Woche für sämmtliche Proben ein positives Resultat, nach 14 Tagen lebten die Cholerabacillen, wie oben, nicht mehr in Nr. 20, wohl aber in Nr. 4; nach zehn Wochen waren dieselben in Nr. 4 bei $8^{\circ}$ abgestorben, bei $22^{\circ}$ aber noch lebensfähig. Der Einfluss der Grösse der Einsaat wurde in einem anderen Experiment mit Wasser Nr. 4 bei $22^{\circ}$ klargestellt. Bei einer Finsaat von 500000 Cholerabacillen auf $400 \mathrm{com}$ Wasser, also dem 20. bis 30. Theil obiger Menge, liessen sich dieselben nach 14 Tagen noch in $10^{\mathrm{cem}}$ des Wassers, nach fünf Wochen noch in $100 \mathrm{~cm}$ nachweisen. Wurden anfänglich nur 5000 Bacillen eingesät, so gelang der Nachweis derselben nur noch nach einer Woche in $100^{\mathrm{cm}}$ Wasser, nicht. mehr nach zwei Wochen.

Beeinflusst nun die Zusammensetzung des Wassers die Conservirung der Choleramikroben? Dass die Zahl der bei Anfang des Versuchs vorhandenen Keime von Wasserbakterien nicht eine ausschlaggebende Bedeutung zu haben braucht, ersieht man aus dem gleichen Verhalten von Nr. 19 und 20, von denen das erstere sich nur durch den Durchgang durch's Sandfilter von dem letzteren unterschied. Dass die chemische Zusammensetzung nicht gleichgültig ist, folgt aus der Thatsache, dass Cholerabacillen, die in destillirtes Wasser unter gleichen Bedingungen wie oben eingesät werden, schon nach einigen Tagen absterben. Immerhin braucht der Gehalt des Wassers an organischen oder anorganischen Bestandtheilen nicht erheblich zu sein, wie das Beispiel von Nr. 18 (aus einem Rohrbrunnen) lehrt, das die Mikroben wenigstens 14 Tage lang conservirte. Für den Einfluss reichlicher organischer Substanzen würden die Wässer Nr. 9 und 10 sprechen, die in der Serie 7 bis 12 allein nach zwei Wochen noch ein positives Resultat ergaben. 
Merkwürdig ist, dass gerade diese beiden Wässer aber auch am reichsten an saprophytischen Mikroorganismen waren, die doch der allgemeinen Anschauung nach durch ihre "Concurrenz" fremden parasitischen. Eindringlingen das Dasein verkürzen sollen! Wenn man aus dem auffälligen Resultat, dass Nr. 4 nach zehn Wochen noch lebensfähige Kommabacillen enthielt, etwas schliessen wollte, so würde die sehr geringe Menge von Wasserbakterien und der ziemlich bedeutende Gehalt an anorganischen Salzen von Bedeutung erscheinen. Aus der Gesammtheit meiner Erfahrungen lässt sich jedoch keine bestimmte Regel ableiten. Die genannten Factoren mögen, der eine in diesem, der andere in jenem Falle von Werth sein.

Einem Jeden, der eigene Erfahrungen über den Einfluss des Lichtes auf das Bakterienleben besitzt, wird es bekannt sein, dass sich derselbe auch im Wasser, namentlich bei genügender Sauerstoffzufuhr äussern kann. Man wird aber gerade, wenn man die Bedeutung des Mediums für das Inkrafttreten dieses Einflusses experimentell verfolgt hat, über die Tragweite des letzteren in Zweifel gerathen können. Im Hinblick auf die Ergebnisse von Buchner ${ }^{1}$ habe ich mit Cholerabacillen einige Experimente angestellt, um die Einwirkung des diffusen Tageslichtes festzustellen. Die Gefässe und Wassermengen sowie die Einsaat waren gleich den bei den ersten Versuchen angegebenen. Wässer Nr. 4 und 20, die ich zu dem Versuche wählte, wurden theils in geschwärztes Papier sorgfältig eingewickelt, theils frei stehend an die äussere Oeffnung eines nach Norden gehenden, hellen, vor directem Sonnenlicht geschützten Fensters gestellt. Die atmosphärische Temperatur in der Versuchszeit schwankte von 15 bis $30^{\circ}$. Jeden Tag wurden alle Flaschen einmal gründlich umgeschüttelt. Nach einer Woche, als die erste Prüfung daraufhin angestellt wurde, erwiesen sich die Cholerabacillen in dem Wasser, das, nach den früheren Erfahrungen zu urtheilen, ziemlich schlecht conservirte (Nr. 20), in der belichteten Flasche abgestorben, in der unbelichteten aber noch lebendig, in beid en Proben von Nr. 4 ebenfalls lebensfähig. Nach 14 Tagen blieben die Kommabacillen in den Culturen aus allen Flaschen aus, während die zu gleicher Zeit angestellten Wasserculturen von Nr. 4 , di ebei $8^{\circ}$ und $22^{\circ}$, im Dunkeln gehalten waren, positiv ausfielen. Wir haben also allerdings eine gewisse Wirkung des diffusen Lichtes zu constatiren; aber auch die in den Controlgefässen wirkenden Einflüsse: der Wechsel der Temperatur und das tägliehe Schütteln (Sauerstoffzufuhr oder Bewegung?) hatten eine merkbare Wirkung! Diese Versuche sind geeignet, auf die Vorgänge bei der sog. Selbstreinigung der Flüsse

${ }^{1}$ H. Buchner. Archiv für Hygiene. Bd. XVIr. S. 179. 
ein Licht zu werfen. Alle drei Factoren: Licht, Temperaturveränderung und Bewegung spielen eine gewisse Rolle, freilich eine praktisch recht beschränkte. Im Gegensatz zu Buchner möchte ich das doch hervorheben.

Nachdem einmal nachgewiesen, wie erheblich die Resistenz des Cholerabacillus im Wasser ist, hat die Frage; ob er auch darin zu einer Vermehrung befähigt sei, verhältnissmässig geringeres Interesse. Die Ergebnisse der früheren Experimente waren, wie schon oben bemerkt, nicht ganz übereinstimmende, soweit sie mit sterilisirtem Wasser vorgenommen wurden. Zum Theil mögen sích diese verschiedenen Resultate dadurch erklären, dass nicht genügend Sorge für die ganz gleichmässige Vertheilung der Bacillen getragen war. Es ist möglich, dass kleinere Verbände von Mikroorganismen und mit diesen auch Spuren von Nährmaterial in das Wasser gerathen sind. Uebrigens entsprach aber auch diese Versuchsanordnung gewiss den manchmal bestehenden natürlichen Verhältnissen. Cholerabacillen werden aus den Entleerungen allerdings häufig in Schleimflocken eingeschlossen in das Wasser gelangen. Andererseits mögen die Differenzen in den Resultaten genannter Autoren auch auf solche in der Zusammensetzung der Wässer selbst zurückzuführen sein.

Ich selbst habe nur wenige Experimente mit Culturen von Kommabacillen in sterilisirtem Wasser angestellt. In einem ersten Versuch kam es mir darauf an, zu sehen, ob die in einem mässig verunreinigten Wasser vorhandenen Stoffe überhaupt im Stande wären, die Vegetation der Choleramikroben zu unterstützen. Es wurde zu dem Zwecke das in Tabelle I unter Nr. 2 genannte Wasser unter aseptischen Cautelen durch Kieselguhr filtrirt und bei $35^{\circ}$ im Vacuum auf den 50. Theil seines Volumens eingedampft. In Reagensgläsern, die mit dieser gelblichen Flüssigkeit gefüllt waren, gediehen Cholerasowohl wie Typhusbacillen schon unmittelbar nach der Einsaat ausgezeichnet. Dasselbe geschah bei 7 facher Concentration des Brunnenwassers. Jetzt richtete ich den Versuch in der Weise ein, dass ich dieselbe Menge Cholerabacillen, nämlich 300000 auf $4 \mathrm{ccm}$, in filtrirter und zweifach concentrirtes, in nicht concentrirtes aber ebenfalls filtrirtes und schliesslich in unfiltrirtes Wasser brachte: In der ersten Probe begann sowohl bei $22^{\circ}$ als bei $37^{\circ}$ unmittelbar nach der Einsaat das Wachsthum, das von 700 Keimen in einer grossen Platinöse in zwei Tagen bis zu 100000 führte. Danach trat ebenso schnell der Abfall ein. Im einfach filtrirten Wasser machte sich bei $22^{\circ}$ zuerst eine deutliche Verminderung der Keime und dann erst eine Vermehrung - von 700 auf 25000 - geltend, bei $37^{\circ}$ begann sofort eine langsame Vermehrung bis etwa zu derselben Ziffer. Im unfiltrirten trat bei beiden Temperaturen sofort eine stetige Verminderung der eingesäten Cholerabacillen ein, während die im Wasser vorhandenen Saprophyten sich üppig vermehrten. Es ist durch 
diese. Versuchsreihe festgestellt, dass das benutzte Brunnenwasser, je stärker concentrirt es war, einen um so besseren Nährboden für Cholerabacillen abgab, dass es ferner im nicht concentrirten, aber filtrirten $\mathrm{Za}-$ stand einem Theil der eingesäten Cholerakeime ein mässiges Wachsthum gestattete, hingegen bei Gegenwart der im Wasser einheimischen Saprophyten die eingebrachten Bacillen allmählich vernichtete. Welch bedeutenden Einfluss auf diese Verhältnisse die chemische Zusammensetzung des Wassers hat, folgt aus einem mit Wasserleitungswasser angestellten Experiment. Bei ähnlicher Einsaat wie oben fand hier sowohl in den filtrirten wie in den unfiltrirten Proben ein plötzliches und stetiges $A b$ sterben der Cholerabacillen statt, und zwar blieb es sich gleich, ob die letzteren ron Culturen abstammten,. die in den gewöhnlichen Nährböden gezüchtet, oder von solchen Bacillen, die vier Wochen lang im Wasser verweilt hatten.

Es war von Interesse, zu constatiren, ob vielleicht diejenigen $W$ ässer, die im unfiltrirten Zustand Cholerabacillen sehr lange zu conserviren geeignet waren, denselben auch eine gewisse Vervielfältigung gestatteten. Wasser Nr. 4 wurde bei $22^{\circ}$ daraufhin geprüft. Es zeigte sich, dass bei einer Einsaat von 500000 bezw. 5000 Cholerabacillen pro $400^{\mathrm{cem}}$ bei einer Temperatur von $22^{\circ}$ die Zahl derselben langsam aber deutlich abnahm. Nach sechs Tagen wuchsen aus beiden Proben von dem zehnten Theil eines Cubikcentimeters keine Cholerakeime mehr; der Einwand, dass dieselben etwa durch die Colonieen der Wasserbakterien am Auswachsen auf den Platten verhindert worden wären, ist dabei vollständig auszuschliessen, da eine Gelatine benutzt wurde, die das Gedeihen der letzteren wirksam beschränkte.

Auf die Wichtigkeit unserer jetzigen, gegen früher erheblich verbesserten Methodik der Wasseruntersuchung auf Cholera ist hier der Ort, hinzuweisen. Die oben mitgetheilten Resultate, welche die sehr bedeutende Widerstandsfähigkeit der Cholerakeime im Wasser beweisen, sind unter Benutzung der von Koch ${ }^{1}$ neuerdings beschriebenen Peptonwassermethode gewonnen worden. Dieselbe gestattet, grössere Wassermengen auf das Vorkommen von Cholerabacillen zu verarbeiten, indem man nur nöthig hat, von einer concentrirten sterilisirten Peptonkochsalzlösung (z. B. zehn Procent Pepton, fünf Procent Kochsalz) so viel zu der Wasserprobe zu mischen, dass eine etwa einprocentige Peptonlösung daraus entsteht. In obigen Experimenten wurden der Regel nach $10 \mathrm{~cm}$ der Peptonstammlösung zu $100 \mathrm{~cm}$ Wasser gegeben und das Gemisch in den Brütofen gestellt. Das dazu brauchbare Gefäss kann beliebig geformt sein

${ }^{1}$ R. Koch. Diese Zeitschrift. Bd. XIV. S. 319. 
und ohne Gefahr offen gelassen werden. Die Sauerstoffzufuhr darf jedenfalls keine beschränkte. sein. Nach 10 bis 24 Stunden werden von der oberflächlichen Schicht der Flüssigkeit gefärbte mikroskopische Präparate angefertigt. Sind Kommabacillen von der Grösse der Cholerabacillen vorhanden, so beweist das, wie schon Koch angiebt, durchaus noch nicht, dass sie wirklich mit letzteren identisch sind. Es kommen in Wăssern aller Art sehr häufig Bakterien vor, die morphologisch den Mikroben der Cholera ausserordentlich ähneln. In etwa 30 Untersuchungen unfiltrirten und filtrirten Oderwassers, die ich in diesem Sommer gemeinschaftlich mit Hrn. Dr. Känsche, Hülfsassistenten des Instituts, gemacht habe, fehlten dieselben selten gänzlich und waren manchmal recht zahlreich vorhanden. Bei meinen Brunnenwasseranalysen bin ich ihnen zwar auch häufig genug, aber doch nicht mit solcher Regelmässigkeit begegnet. Namentlich möchte ich für die letzteren nach meiner Erfahrung behaupten, dass, wenn im mikroskopischen Präparat vorwiegend Kommabacillen von der Form der Cholerapilze auftreten, dies mindestens ein sehr bedeutendes Verdachtsmoment gegen das betreffende Wasser darstellt. Andererseits gilt freilich die Regel nicht, dass, wenn Cholerabacillen im Wasser vorhanden sind, dieselben in der Peptonwassercultur stets in reichlichster Menge auftreten. Nach zehn Stunden brauchen z. B. Kommabacillen mikroskopisch nicht nachzuweisen und nach 24 Stunden können sie bedeutend in der Minderheit vorhanden sein, trotzdem erhält man im weiteren Verlauf der Untersuchung unzweifelhafte Cholerabacillen. Der Zeitpunkt, den man am besten zur mikroskopischen Untersuchung und weiteren Verarbeitung der Wasserculturen benutzt, ist nach meiner Erfahrung der Termin von 24 Stunden. Ich wähle diesen, weil er in den schwierigen Fällen mehr Sicherheit bietet, und weil es im Allgemeinen bei solchen Wasseranalysen nicht auf einige Stunden mehr oder weniger ankommt.

Für die Untersuchung von Fäces auf Cholerabacillen ist die Peptonwassermethode entschieden leistungsfähiger als in unserem Falle. Schon mit dem Mikroskop kann hier aus der Cultur in Peptonlösung fast ${ }^{1}$ mit Sicherheit die Diagnose auf Cholera gestellt werden, und zwar gelingt das allermeist schon innerhalb der ersten zehn Stunden. Trotzdem ist unzweifelhaft die Peptonmethode als ein grosser Fortschritt auch für die Wasseranalyse zu betrachten. Concurriren könnte in manchen Fällen die ältere Schottelius'sche Methode. Deren Leistungsfähigkeit wird durch die oben berichtete Thatsache illustrirt, dass Pasquale mit ibrer Hülfe

1 Vgl. übrigens die Mittheilungen von Kutscher, Deutsche medicin. Wochenschrift, 1893, Nr. 49, und Zörkendörfer, Prager medicinische Wochenschrift, 1898, Nr. 43 u. 44.

Zeitschr. f. Hygiene. XVII. 
in einem stark verunreinigten Wasser neun Tage lang Cholerabacillen nachweisen konnte. Indessen hat uns ein wiederholter Vergleich der beiden Verfahren doch die. Ueberlegenheit der. Peptonwassermethode ergeben. Es liegt das offenbar daran, dass die einfache Peptonlösung einer ganzen Reihe von :Bakterien nicht als Nährboden genügt. Annähernd dasselbe Ziel kann man auch beim Bouillonverfahren und zwar dadurch erreichen, dass man der Fleischbrühe einen stärkeren. Alkalescenzgrad verleiht. Auch so lässt sich das Wachsthum zahlreicher Mikroorganismen verhindern, während die Cholerabacillen gleichmässig gut gedeihen. Für die Praxis bietet jedoch die Anwendung der Peptonlösung als Nährmittel den unzweifelhaften Vortheil, dass sie bequemer herzustellen und in concentrirtem Zustande aufzubewahren ist. Wenn hingegen Stutzer und Burri als einen weiteren Vorzug der letztereń die Möglichkeit betrachten, durch Anstellung der Cholerarothreaction schon in der Mischcultur ein icheres diagnostisches Kriterium zu gewinnen, so ist das ein Irrthum, denn, wie mir zahlreiche Erfahrungen bewiesen haben, kann schon eine Minorität anderer Bakterien im Peptonwasser das Zustandekommen der Rothreaction verhindern und andererseits trotz des vollständigen Fehlens von Cholerabacillen in der Peptonlōsung, die genannte Reaction positiv ausfallen. Auf diese nicht unwichtigen Verhältnisse wird weiter unten zurückzukommen sein. Zunächst interessirt uns weiter die Frage, wie wir die in der Peptonwassercultur mehr oder weniger reichlich angehäuften Kommabacillen zu isoliren und mit den Erregern der Cholera zu identificiren haben. Sehr hāufig wird die alte Methode zum Ziele führen: man giesst Platten in gewöhnlicher Nährgelatine und sucht diejenigen Colonieen, die dem Bilde der Choleracolonieen entsprechen, zu isoliren. Gerade bei der Wasseruntersuchung stellen sich dabei dreierlei Schwierigkeiten heraus: erstens giebt es hier Colonieen, die in gewissen Stadien viel Aehnlichkeit mit denen der Cholera haben, zweitens ist gewöhnlich die Zahl der stark verflüssigenden Bakterien recht gróss, so dass man zweifelhafte Platten nicht lange genug beobachten kann, drittens sind die Choleracolonieen in gewöhnlicher Nährgelatine in ihrer späteren Fntwickelung nicht so charakteristisch, als man wünschen könnte. R. Koch berichtet über eine im Institut für Infectionskrankheiten ausgebildete Methode, die möglichst schnell zum Ziele führen soll. Eine Platinöse des Peptonwassers wird auf Agarplatten ausgestrichen, die Colonieen, die sich auf denselben nach 6-10 stündigem Aufenthalte im Brutofen gebildet haben, sind mit blossem Auge und unter dem Mikroskop bei schwacher Vergrösserung zu durchmustern. Die der Cholerabacillen sind zwar nicht so charakteristisch wie diejenigen auf Gelatine, aber doch durch gewisse Merkmale ausgezeichnet. Man fertigt von den verdächtigen Colonieen 
mikroskopische Präparate an, diejenigen, die Kommabacillen gleich denen der Cholera enthalten, werden auf Peptonwasser und schräg geneigte Agarflächen abgeimpft, im ersteren stellt man frühestens nach. sechs Stunden die Schwefelsänrereaction an, nach positivem Ausfall derselben inficirt man mit einer Oese der letzteren ein Meerschweinchen.

Praktisch bewährt zu haben scheint sich diese Methode, grössere Sicherheit würde sie bieten, ;wenn man zu gleicher Zeit von den Agarcolonieen aus Gelatineplatten giessen würde und deren Wachsthum verfolgte. Allzu schnell erreicht man übrigens auf diese Weise den Zweck der Identificirung eines Kommabacillus mit dem Cholerabacillus auch nicht. Nur wenn man sich auf die Ausschliesslichkeit der Cholerarothreaction verlässt, hat man schon binnen mindestens zwölf Stunden ein Resultat. Leider ist man dazu aber nicht mehr berechtigt.

Im hiesigen Institut ist eine Methode ausgebildet worden; die verschiedene Vorzüge zu haben scheint. Der Ausgangspunkt für die betreffenden Experimente war die Frage, bei welchem Alkalescenzgrad der Nährgelatine die Choleracolonieen eine am meisten charakteristische Form darböten und sich am schnellsten entwickelten. Die Antwort daraut lautete: bei einer Alkalinität, die diejenige des am meisten gebräuchlichen Nährbodens um 1/4 Proc. Gehalt an (wasserfreier) Soda übertrifft. Bei Verwendung dieser Gelatine stellte es sich nun heraus, dass sie für eine ganze Reihe von Mikroorganismen unbrauchbar war. Es war damit ein Mittel gegeben, die Cholerabacillen aus einem Gemisch mit anderen Bakterien, z. B. aus Fäces leichter herauszuzüchten. Schon die ersten Versuche mit choleraverdächtigen Stühlen lehrten die Nützlichkeit des hohen Alkaligehaltes der Gelatine. Bei meinen Wasseruntersuchungen trat zwar auch dieser Vortheil deutlich hervor, indessen doch nicht in dem Maasse, wie bei den Analysen der Fäces. Die verflüssigenden Bakterien des Wassers blieben trotz des Alkalizusatzes zum Nährboden recht stōrend. Durch verschiedene einfache Modificationen gelangte Verfasser zu besseren Resultaten. Statt des Fleischsaftes wurde Fleischextract, statt der 10 procentigen Gelatine eine 15 procentige verwendet. Man erreicht dadurch

1. den praktischen Vortheil, dass der Nährboden in wenigen Stunden herzustellen ist $\left(1 \frac{1}{2}\right.$ Procent Fleischextract, 1 Procent Pepton, 1/2 Proc. Kochsalz, 15 Procent Gelatine, 60 cem einer 10 procentigen Sodalösung ${ }^{1}$ );

2. dass er der erhöhten Temperatur des Hochsommers leichter widersteht;

1 Genauer: einer doppelten Normallösung (10.6 Procent) von frisch durch Glühen doppeltkohlensauren Natrons hergestellter Soda. 
3. dass die Verflüssigung der Gelatine bedeutend langsamer vor sich geht;

4. dass die Form der Choleracolonieen in dieser Gelatine Tage lang charakteristisch bleibt. In der That hat Verfasser bei seinen zahlreichen Wasseranalysen kein Bacterium gefunden, das in allen Stadien seiner Coloniebildung mit dem Cholerabacillus übereingestimṃt hätte. Nach wie vor ist also auf die Coloniebildung des Choleravibrio das Hauptgewicht zu legen. Ich unterlasse es absichtlich, eine Schilderung desselben zu geben. Auch die vorhandenen Photographieen, so gelungen sie sind, können hier die eigene vielfache Anschauung nicht ersetzen. Vielfache, sage ich, denn zwischen den Colonieen des Choleravibrio kommen zahlreiche Unterschiede vor, nicht nur solche, die durch Verschiedenheiten in der Zusammensetzung des Nährsubstrates bedingt sind, sondern auch solche, die den Bakterien verschiedenen Ursprungs selbst eigenthümlich sind. Wir gelangen damit zu der Frage nach der Variabilität des Choleravibrio. Schon wenn man die Colonieen vergleicht, die bei Fällen echter Cholera des Menschen aus den Fäces herausgezüchtet werden, ergeben sich gewisse Differenzen. Auf dieselben hat man bisher weniger geachtet, als auf ihre gemeinsamen Charaktere, immerhin bemerkt Koch neuerdings, dass ihm auch sogenannte atypische Colonieen in den Fäcesplatten aufgestossen seien. Schon lange kennt man die letzteren von den im Laboratorium gezüchteten Culturen her, und Friedrich ${ }^{1}$ hat eine ziemlich vollständige Beschreibung eben dieser Formen geliefert. Praktisch scheint ihre Kenntniss für die Analyse des Wassers eine grössere Bedeutung zu haben, als für die der Fäces. Denn bei künstlicher Einsaat der Cholerabakterien in's. Wasser kann man eine erhebliche Variabilität derselben, gerade was die Form der Colonieen anlangt, beobachten, und zwar auch dann, wenn man ganz frische, d. h. wenige Tage aus der Fäces isolirte Culturen zu den Experimenten benutzt. Unter natürlichen Verhältnissen wird sich das wohl ähnlich verhalten. Wir finden hier typische neben ganz atypischen Colonieen in demselben Wasser oder auch in einem Wasser bloss typische, in einem anderen nur atypische. Man kann nicht etwa die allgemeine Regel aufstellen, dass das Wachsthum um so mehr von der Norm abweiche, je länger der Aufenthalt des Cholerabacteriums im Wasser dauere. So z. B. wuchsen aus einem zehn Wochen vorher mit Cholerabacillen inficirten Wasser ausschliesslich charakteristische Colonieen. Die näheren Einflüsse, die hier in's Spiel kommen, kennen wir nicht. Jedenfalls ist die Neigung der Choleraorganismen zum atypischen Wachsthum eine ausserordentlich ver-

1 P. Friedrich, Arbeiten aus dem Kaiserl. Gesundheitsamt. Bd. VIII. S. 87. 
schiedene. In einem Falle constatirte ich schon bei einer Cultur, die wenige Wochen vorher in Neapel isolirt war, dass aus einem davon abgeimpften Gelatinestich ganz atypische Colonieen hervorgingen, die auch bei weiterer Umzüchtung diesen Charakter behielten. In anderen Fällen bleibt die charakteristische Form der Coloniebildung : auch nach Jahre langer Züchtung erhalten. Ganz entschieden zu bestreiten ist, dass, wie Friedrich behauptet, jede Abweichung von dem Typus nur als eine vorübergehende $\mathrm{zu}$ betrachten sei. Ich habe eine seit einigen Monaten atypisch wachsende Cultur in der verschiedensten Weise zum ursprünglichen Typus zurückzubringen gesucht. Es gelang nicht, auch nicht durch wiederholte Verimpfung von Meerschweinchen auf Meerschweinchen. Nachweislich wuchs die Virulenz durch diesen Process erheblich und trotzdem blieb die Form der Colonieen wie sie vorher gewesen.

Aehnliche Verschiedenheiten gelten für die Morphologie des Cholerabacillus. Doch ist zu bemerken, dass eine atypische Coloniebildung durchaus nicht mit Abweichungen vom Formentypus Hand in Hand zu gehen braucht und umgekehrt. Die letzteren bestehen wesentlich darin, dass die verhältnissmässig dickeren und kürzeren Kommabacillen länger und schlanker werden, und dass die ursprünglich geringe Neigung zur Bildung grösserer Verbände zunimmt. Auch diese Eigenschaften können recht beständig sein, so hatte ich z. B. schon vor mehreren Jahren in Neapel Culturen neben einander, von denen die eine stets nur kurze Kommas, die andere schöne Spirillen zeigte. Auch im Thier können diese Formverschiedenheiten persistiren. Ob unter natürlichen Verhältnissen, z. B. bei den Cholerabacillen aus verschiedenen Epidemieen, ähnliche Differenzen sich ergeben, verdiente geprüft zu werden. Nach künstlicher Einsaat in Wasser kann man derartige Variationen schon ziemlich schnell - nach 8 bis 14 Tagen z. B. - beobachten.

Die Cholerarothreaction hat für die Diagnostik eine unbestreitbare Bedeutung, weil die Fähigkeit der Cholerabakterien, Nitrate zu Nitriten zu reduciren und zu gleicher Zeit aus eiweissähnlichen Stoffen Indol zu bilden, constant zu sein scheint. Praktische Schwierigkeiten für den Ausfall der Reaction entstehen freilich durch die veränderliche $\mathrm{Zu}$ sammensetzung des Nährsubstrates. Man kann dieselben dadurch erheblich verringern, dass man zur Anstellung der Reaction stets dieselbe einfache Peptonkochsalzlösung benutzt, die man ein für alle Male auf ihre Brauchbarkeit geprüft hat. Auf welche wechselnden Bestandtheile es hier ankommt, hat $\mathrm{Petri}^{1}$ und neuerdings wieder Bleis $\mathrm{ch}^{2}$ nachgewiesen.

\footnotetext{
1 Petri, Arbeiten aus dem Kaiserl. Gesundheitsamt. Bd. VI. S. 1.

${ }^{2}$ Bleisch, Diese Zeitschrift. Bd. XIV. S. 103.
} 
Alles hängt von dem Peptonpräparat, das man benutzt, ab. Leider arbeiten auch dieselben Fabriken nicht ganz gleichmässig. Man kann sïch daher nur so helfen, dass man sich ein grōsseres Quantum Pepton kommen lässt und dasselbe auf das Zustandekommen der Reaction prüft. Freilich wird man, trotzdem dass man nach dieser Regel verfährt, nicht immer auch bei unzweifelhaften Choleraculturen Reactionen gleicher Intensität erhalten. Es bestehen eben auch hier gewissermassen individuelle, vielleicht auch vererbliche Differenzen der Cholerabakterien verschiedenen Jrsprungs. Man begreift das leicht, wenn man an die sicher vorkommenden Verschiedenheiten in der Wachsthumsintensität der Choleraculturen denkt. Dieselbe kann, wie z. B. Zählungen der in Agarculturen auf gleicher Oberfläche und in gleicher Zeit entwickelten Cholerabakterien ergeben, vom 1-20 fachen variiren. Ob wirklich Cholerabakterien vorkommen, die, auch das Optimum der Zusammensetzung der Nährlösung vorausgesetzt, die Rothreaction nicht geben, muss erst von Neuem festgestellt werden, da die älteren Angaben nicht genügend mit den das Substrat betreffenden Verhältnissen gerechnet haben. An sich wäre die Möglichkeit nicht zu leugnen, da wir wissen, dass die fermentativen Eigenschaften der Mikroorganismen im Allgemeinen und der Choleramikroben im Besonderen allerdings zu beeinflussen sind. Bewiesen scheint das für das Verhalten der letzteren in der Milch; wir kennen Varietäten des Choleravibrio, die dieselbe coaguliren und andere, die sie anscheinend unvèrändert lassen. Es verdient festgestellt zu werden; wieviel von dieser Wirkung der Intensität der Säurebildung und wieviel dem Vorhandensein eines. Fermentes zuzuschreiben ist. Nach meinen einschlägigen Erfahrungen bringen frisch isolirte Culturen die Milch nicht immer zur Gerinnung, andererseits können ältere diese Eigenschaft Jahre lang festhalten.

Das pathogene Vermögen des Choleravibrio Thieren gegenüber ist wieder in der letzten Zeit vielfach Gegenstand experimenteller Untersuchung gewesen. Von der einen Seite wird behauptet, dass dasselbe im Wesentlichen constant sei, ron der anderen, dass es erheblichen Schwankungen unterliege. Ein Cmstand, der jedenfalls die Verständigung in dieser Frage erschwert, ist der, dass von den verschiedenen Parteien zum grossen Theil nicht derselbe Maassstab zur Prüfung der Virulenz angewendet wird. Derjenige, der nach „Oesen Agarcultur" rechnet, wird zwar, wenn er sich auf diese Methode eingearbeitet hat, unter sich leidlich vergleichbare Ergebnisse erhalten, ebenso derjenige, der nach Bruchtheilen einer aufgeschwemmten Agarcultur misst. ${ }^{1}$ An verschiedenen

1 Aber diese letztere Methode ist deswegen entschieden unsicherer, weil sie nicht die ungleiche Wachsthumsintensität der Culturen verschiedenen Ursprunges 
Orten und von anderen Forschern angewendet, werden aber diese Methoden wenig übereinstimmende Resultate ergeben. Hinzu kommt, dass durchaus nicht immer mit Culturen gleichen Alters und mit Versuchsthieren von derselben Disposition gearbeitet wird. Zwischen den Bacillen aus Culturen ungleichen Alters können nicht nur Unterschiede in der Virulenz bestehen, sondern vornehmlich wird auch die Zahl't der in solchen Culturen im lebenden Zustand vorhandenen Bakterien variiren. Dass Meerschweinchen von ungleichem Gewicht nicht etwa in derselben Weise reagiren, wenn sie ihrem Gewicht proportionale Dosen der Virus erhalten, wie es zum Theil angenommen wird, folgt aus einigen meiner Experimente.

Um einen überall anwendbaren Maassstab für die Virulenz zu gewinnen, ist es vor Allem nöthig, von Culturen gleichen Alters und auf demselben Nährboden auszugehen, die Zahl der zur Injection gelangenden Cholerabacillen festzustellen, und Thiere von gleichem Gewicht zu wählen. Bei jungen, z. B. 16 stündigen Culturen auf Glycerinagar, der noch seinen ursprünglichen Wassergehalt besitzt, ist es ein Leichtes, durch Schütteln mit steriler Bouillon eine gleichmässige Emulsion herzustellen, und deren Keimzahl nach sachgemässer Verdünnung zu bestimmen.

Auf diese Weise habe ich das pathogene Vermögen einer wenige Wochen vorher im Institut solirten Choleracultur geprūft. Dabei ergab sich Folgendes:

1. Meerschweinchen $(205 \mathrm{grm})$ erhält intraperitoneal 100 Mill. Bacillen, $\dagger$ in 12-20 Stunden.

2. Meerschweinchen $(195 \mathrm{grm})$ erhält intraperitoneal 200 Mill. Bacillen, $\dagger$ in 12-20 Stunden.

3. Meerschweinchen $(398 \mathrm{grm})$ erhält intraperitoneal 400 Mill. Bacillen, bleibt leben.

4. Meerschweinchen $(430 \mathrm{grm})$ erhält intraperitoneal 900 Mill. Bacillen, + in 20 Stunden.

Während hier die tödtliche Dosis für Meerschweinchen von ca. $200 \mathrm{grm}$ noch unter 100 Mill. Bacillen lag, war dieselbe in einem anderen Falle noch nicht mit 1700 Mill. erreicht. Es betraf das eine Cultur, die mehrere

berücksichtigt. In einem meiner Versuche fand ich z. B. bei Culturen, die von verschiedenen Fällen stammten, unter sonst gleichen Verhältnissen in der einen die 20-fache Zahl von Bakterien wie in der anderen.

1 Z. B. fand ich unter sonst gleichen Bedingungen in einer eintägigen Cultur 1300 Nillionen Bacillen, in einer dreitägigen (wie die erstere bei $37^{\circ}$ gewachsen) nur noch den zehnten Theil, 130 Millionen lebendig. 
Monate in den gewöhnlichen Nährböden und darauf vier Wochen in concentrirtem Wasser gezüchtet worden war. Es kann also nicht zweifelhaft sein, dass das pathogene Verhalten der Choleramikroorganismen in der That recht erhebliche Variationen durchmachen kann. Dass die Verminderung der Virulenz in unserem letzten Falle auf den Aufenthalt in einem recht kümmerlichen Substrat zurückzuführen wäre, könnte man aus der Thatsache schliessen, dass dieselbe Cultur, nicht in Wasser sondern in der üblichen Weise fortgeführt, Meerschweinchen des nämlichen Gewichts mit 450 Mill. Bacillen tödtete. Ob praktisch diese Frage von besonderem Werthe ist, muss jedoch ungewiss bleiben, da wir so gut wie nichts über die :Wege wissen, auf denen die Virulenz wieder hergestellt werden kann. In dieser Beziehung ist ein Versuch Metschnikoff's ${ }^{1}$ von grossem Interesse. Unter einer Reihe von Personen, die Culturen von Cholerabacillen verschluckten, wurde gerade diejenige am stärksten ergriffen, die viele Jahre schon im Laboratorium gezüchtete Cholerabacillen von sehr geringer pathogener Wirkung auf Meerschweinchen einnahm!

Für die Diagnose des Cholerabacillus im Wasser ist es nothwendig, seine in den besprochenen Beziehungen hervortretende Variabilität zu berücksichtigen. Bis in die jüngste Zeit wurden zwar gerade aus dem Wasser keine Bakterien berausgezüchtet, die eine Verwechselung mit dem Cholerabacillus nahegelegt hätten; in den letzten beiden Jahren sind aber zahlreiche solche Funde gemacht worden. Ziehen wir nur morphologische Charaktere in Betracht, so sagt uns R. Koch, dass allein in seinem Institut etwa ein Dutzend choleraähnliche Bakterien aus Wasser verschiedener Herkunft herausgezüchtet worden seien. Im hiesigen Institut wurde auf die Isolirung solcher Mikroorganismen kein besonderer Werth gelegt, ihr Vorkommen konnte aber, wie oben angegeben, in sehr zahlreichen Wässern schon durch die mikroskopische Untersuchung der Peptonculturen sicher gestellt werden. Was die Form der Colonieen auf Gelatineplatten anbetrifft, so wurde zwar von mehreren Seiten die Aehnlichkeit mancher fremden Colonieen mit denen der Cholera bemerkt, immer liessen sich hier aber zugestandenermassen bei fortgesetzter Beobachtung deutliche Differenzen constatiren. Nach meiner eigenen Erfahrung wird durch die Benutzung der 15 procentigen stark alkalischen Extractgelatine diese Differenzialdiagnose erheblich erleichtert. Die Cholerarothreaction ist insofern ron geringerem Werthe, als im Wasser viele Bakterien vorkommen, die in Reincultur und eventuell auch in Mischculturen dieselbe geben. Schon unsere ersten Versuche lehrten uns,

1 Metschnikoff, Annales de l'Institut Pasteur. 1893. Nr. 10. 
dass es absolut unstatthaft ist, mit Stutzer und Burri aus einer charakteristischen Rothfärbung der Wasserpeptonculturen nach Schwefelsäurezusatz auf das Vorhandensein von Cholerabacillen darin zu schliessen und umgekehrt. Ebenso oft wie die Reaction trotz der Gegenwart zahlreicher Choleramikroben negatir blieb, fiel sie bei dem gänzlichen Fehlen derselben positiv aus. Anders steht die Sache, wenn man zu gleicher Zeit die morphologischen Verhältnisse und die Cholerarothbildung berücksichtigt. Gerade bei den im Wasser vorkommenden Spirillen ist es die entschiedene Regel, dass sie nicht sowohl Nitrat zu Nitrit reduciren, als Indol produciren, also mit Schwefelsäure keine Rothfärbung geben. Nach den im Institute von R. Koch gemachten Erfahrungen wäre der Mangel pathogenen Vermögens ein zweiter Charakter dieser Kommabacillen des Wassers im Gegensatz zu denen der Cholera. Leider gelten jedoch beide Regeln nicht ohne Ausnahme. Im hiesigen Institut hat Hr. Dr. Känsche ${ }^{1}$ aus dem Wasser der Przemsa ein Spirillum isolirt, das in seiner Form durchaus den Choleraorganismen entspricht, ferner wie diese in Reinculturen die Rothreaction giebt und in den üblichen Dosen für Meerschweinchen ebenso pathogen ist. Auf Platten bestehen jedoch unzweifelhafte Differenzen zwischen beiden Culturen. Aehnliche, aber doch ebenfalls unter sich und rom Choleramikroben differenzirbare Kommabacillen sind neuerdings von Rubner ${ }^{2}$ und Heider ${ }^{3}$ beschrieben worden. Schwieriger erscheint die Unterscheidung eines Bacteriums, das Dunbar ${ }^{4}$ des Oefteren aus der Elbe isolirt hat. Nach der Darstellung dieses Autors könnte man an die völlige Identität der Charaktere seines Kommabacillus mit dem der Cholera glauben, wenn der Autor selbst nicht diesen Uebergang durch dis eigentlich unerwartete Bemerkung erschütterte: „Jedoch ist das Gesammtbild, welches man bei längerer Beobachtung dieser Wasservibrionen erhält, derartig, dass man sich sagen muss, dass sie verschieden sind von den Choleravibrionen, wie man sie aus dem Darmtractus Cholerakranker zu isoliren pflegt." Ein sicheres Urtheil über diesen Befund D un bar's ist natürlich dadurch unmöglich gemacht, zumal da genaue Angaben über das Verhalten des genannten Bacillus gegenüber Meerschweinchen und Tauben nicht vorliegen. Immerhin beachtenswerth ist das zeitliche Zusammentreffen der Beobachtungen des Autors über das Elbwasser mit dem erneuten Ausbruch der Seuche in Hamburg selbst. Die Möglichkeit, dass

1 Die genaue Beschreibung dieses Bacteriums wird an anderer Stelle erfolgen.

${ }^{2}$ Rubner, Hygienische Rundschau. 1893. Nr. 16.

${ }^{3}$ Heider, Centralblatt für Bakteriologie. Bd. XIV. Nr. 11.

4 Dunbar, Deutsche medicinische Wochenschrift. Nr. 33. Vgl. auch die jüngst erschienene Mittheilung des genannten Autors in den Arbeiten des Kaiserl. Gesundheitsamtes. 1894. Bd. IX. Hft. 2. 
die Kommabacillen Dunbar's nichts anderes als Cholerabacillen waren, ist darnach wohl denkbar. ${ }^{1}$ Jedenfalls sind wir bis jetzt noch nicht zu der Annahme berechtigt, dass etwa neben dem Erreger der Cholera noch andere für den Menschen unschuldige Mikroorganismen im Wasser vorkämen, die von den ersteren durch die uns bisher zur Verfügung stehenden diagnostischen Mittel nicht zu unterscheiden. wären.

Nächst dem Cholerabacillus interresirt uns der Krankheitskeim des Abdominaltyphus, dessen Verbreitung durch das Wasser. schon lange vor seiner wirklichen Entdeckung für möglich gehalten worden ist. Wir verzichten auf die Besprechung der einschlägigen recht reichhaltigen Litteratur. Dass Typhusepidemieen häufig durch das Wasser vermittelt werden, kann als eine erwiesene Thatsache betrachtet werden, die hygienische Praxis bringt fast täglich neue Beweise dafür. Das Wasser kommt hierbei nicht nur in Betracht, so weit es zum Genusse dient, sondern auch als Gebrauchswasser, das z. B. zum Spülen von Milchgefässen Verwendung findet. Seitdem man den Typhusbacillus kennt, ist der Versuch sehr bäufig gemacht worden, ihn im verdächtigen Wasser nachzuweisen, meist ohne Erfolg. Wir dürfen sogar noch weitergehen und behaupten, dass bis jetzt höchstens für einige wenige Fälle die Wahrscheinlichkeit, den Typhuskeim wirklich im Wasser gefunden zu haben, vorliegt; dass es auch nur ein einziges Mal mit Sicherheit gelungen sei, wäre zu viel gesagt. Gerade die neueste Zeit hat Vorsicht in dieser Beziehung gelehrt, wir wissen jetzt, dass kein einziges der bisher bekannten diagnostischen Merkmale dem Typhusbacillus allein zukommt, obwohl die Zahl der uns zur Verfügung stehenden Kriterien gegen früher erheblich vermehrt ist. ${ }^{2}$ Trotzdem es aber mit dem directen Nachweis dieses Mikroorganismus im Wasser schlechter bestellt ist als mit dem des Choleraspirillums, liegen gewichtige Gründe vor, die es wahrscheinlich machen, dass der Typhuserreger, wenn er einmal in's Wasser gelangt ist, leichter dem Kampf um's Dasein in demselben widersteht, als der Kommabacillus. Schon nach allen sonstigen Erfahrungen sind Typhusbacillen bedeutend resistenter als die Choleramikroben; überträgt man beide Arten von Mikroorganismen unter gleichen Bedingungen in sterilisirtes Wasser verschiedener Zusammensetzung, so halten es die ersteren darin viel länger aus als die letzteren. Im Breslauer Leitungs-

\footnotetext{
${ }^{1}$ Inzwischen ist durch die oben schon angeführte Arbeit von Katscher (Deutsche medicinische Wochenschrift, 1893, Nr. 49) als Unterschied zwischen dem Choleravibrio und dem von Dunbar gefundenen das Phosphorescenzvermögen des letzteren festgestellt worden.

${ }^{2}$ Vgl. die darauf bezüglichen Ausführungen in den Untersuchungen über Dysenterie und Leberabscess von Kruse u. Pasquale. Diese Zeitschr. Bd. XVI. S. $59 \mathrm{ff}$.
} 
wasser (filtrirtem Oderwasser) blieb z. B. die Zahl der eingesäten Typhusbacillen viele Tage lang annähernd constant, während die der Choleraspirillen schnell abnahm. Wenn in meinen Versuchen die Verhältnisse so günstig lagen, dass ein Wachsthum der Choleramikroben eintrat, wie z. B. im concentrirten oder auch einfach filtrirten Brunnenwasser Nr. 2, so geschah das gleiche bei den Typhusbacillen. Die Experimente, die von früheren Autoren in nicht sterilisirtem Wasser angestellt worden sind, haben gleichfalls für die Erreger des Typhus günstigere Zahlen ergeben, als für die der Cholera (Kraús, Karlinski) ${ }^{1}$. Die ersteren waren z. B. noch am fünften bis sechsten Tage, die letzteren aber kaum noch am zweiten Tage zu constatiren. Bei Vergleichung dieser Resultate muss ausserdem berücksichtigt werden, dass die angewandte Methode - directe Vertheilung des Wassers auf Gelatineplatten - für den Nachweis der Typhusbacillen viel ungünstiger war, weil nur die oberflächlichen Colonieen bei der Diagnose in Betracht kommen konnten, als für die Choleraspirillen, die auch in den tiefliegenden Colonieen leicht erkenntlich sind. Man hat daher nach den vorliegenden Erfahrungen wohl ein Recht anzunehmen, dass die Keime des Typhus sich besser im Wasser conserviren als die der Cholera. Nun haben aber die oben wiedergegebenen ausgedehnten, mit Hülfe der Peptonwassercultur angestellten Versuche eine sehr beträchtliche Haltbarkeit der Choleraspirillen in natürlichen Wässern jeder beliebigen Zusammensetzung ergeben, um so mehr gilt dieselbe Eigenschaft für die Typhusbacillen. Es ist mit grosser Wahrscheinlichkeit darauf zu rechnen, dass die Lebensfähigkeit der letzteren im Wasser mindestens nach Wochen zählt.

Wenn ihr directer Nachweis darin nur in Ausnahmefällen gelingt, so liegt das an unserer unvollkommenen Untersuchungsmethode. Bis jetzt haben wir noch kein Mittel, die Typhusbacillen aus jedem Bakteriengemisch in ähnlicher Weise herauszuzüchten wie die Choleraspirillen mittels des Peptonverfahrens. Es sind zwar zu diesem Behufe verschiedene Vorschläge gemacht worden, so ron Chantemesse, Widal, Thoinot, Vincent, Parietti. ${ }^{2}$ Das zu Grunde liegende Princip ist

1 Vgl. ausser den oben citirten Arbeiten von Kraus a. Karlinski noch die zweite von Karlinski (Archiv für. Hygiene, Bd.X, S. 464) und Hüppe (Journal für Gasbeleuchtung und Wasserversorgung, 1887): Die hygienische Beurtheilang des Trinkwassers vom biologischen Standpunkte. In einigen Versuchen konnte der Autor die Typhusbacillen sogar noch am 20. Tage (70 Typhusbacillen auf 700000 Wasserbakterien) and am 30. Tage (70 Typhusbacillen anf 500000 Wasserbakterien) nach. weisen (!)

2 Vgl. für den ganzen folgenden Abschnitt die Untersuchung von Germano und Maurea in den Arbeiten des bakteriologischen Laboratoriums der zoologischen Station zu Neapel (Ziegler's Beitr. z. pathol. Anä. u, s. w., Bd. XII, Hft. 3, S. $494 \mathrm{ff}$ 
überall wesentlich dasselbe. Es wird das verdächtige Gemisch, also in unserem Fall Wasser, mit einem flüssigen Nährmedium, etwa Bouillon, vermengt und dazu ein gewisses Quantum eines Antisepticums, das die Typhusbacillen nicht schädigt, aber eine ganze Reihe anderer Bakterien rom Wachsthum ausschliesst, zugesetzt. Als solche entwickelungshemmende Stoffe dienen Carbolsäure (Chantemesse und Widal), Salzsâure (Parietti), Citronensäure und Methylviolett (Uffelmann), $\alpha$-Naphthol, (Rawitsch-Stcherba). ${ }^{1}$ Vincent vermehrt die Wirksamkeit des Desinficiens noch durch Züchtung bei höherer Temperatur $\left(42^{\circ}\right)$. Es ist nicht zu leugnen, dass auf diese Weise eine Art Auslese aus dem zur Untersuchung kommenden Bakteriengemisch stattfindet; namentlich werden die verflüssigenden Bakterien zum grössten Theil dadurch eliminirt; der Versuch mit . Reinculturen von Typhusbacillen ergiebt auch, dass diese unter den genannten Bedingungen ganz gut gedeihen; anders wird es, wenn mit Bakteriengemischen operirt wird, wie Experimente, die Verfasser in Gemeinschaft mit Germano und Maurea anstellte, dargethan haben: dann werden die Typhusbacillen durch eine Gruppe von Mikroorganismen, deren Vertreter geradezu allgegenwärtig zu sein scheinen, verdrängt, nämlich durch typhusähnliche Bakterien. Es ist das nicht wunderbar, wenn man bedenkt, dass die letzteren die Typhuskeime meist erheblich an saprophytischer Wachsthumsenergie und auch an Resistenz gegenüber desinficirenden Einflüssen übertreffen. Es scheint deswegen angebracht, auf solche Vorculturen in flüssigen Nährböden lieber zu verzichten und die Bakteriengemische, die verdächtig sind, Typhusbacillen su enthalten, direct der Einwirkung obengenannter Mittel zu unterwerfen. Man hat nur nöthig, statt der gewöhnlichen Nährgelatine eine solche mit Zusatz von Carbolsäure (0.05 bis 0.1 Procent) oder Salzsäure, oder einfacher eine nicht vollständig neutralisirte Gelatine zur Plattencultur zu verwenden. Die von Holz vorgeschlagene Kartoffelgelatine entspricht demselben Zweck, weil sie sauer ist.

Es gilt die Regel, dass, wie für die Cultur der Choleraspirillen eine mehr alkalisohe Beschaffenheit des Nährbodens, so für die Typhusbacillen eine mehr saure Reaction desselben erwünscht ist. Schon diejenige Nährgelatine, die bis zu dem Grade mit Sodalösung neutralisirt wird, dass sie blaues Lakmuspapier nicht mehr röthet (33 bis $35^{\mathrm{ccm}} 10$ procentige Sodalösung ${ }^{2}$ ), ist entschieden $\mathrm{zu}$ alkalisch für $\cdot$ die

1 Rawitsch u. Stcherba, Zur Frage des Nachweises der Typhusbakterien in Wasser und Fäces. Aus dem bakteriologischen Laboratorium des Ujazdow'schen Militärhospitals in Warschau. Wojenno medic. Journal. 1892. Bd. IV. Referat in Bygienische Rundschau. 1893. Nr. 9.

${ }^{2}$ Aus geglühter Soda hergestellt. 
Typhuskeime, deren Colonieen nur langsam und wenig charakteristisch darin wachsen. In der That ist ihre Reaction schon von vornherein nicht ,neutral" zu nennen, wie es häufig geschieht, sie wird aber nach dem Kochen, d. h. nach dem völligen Entweichen der nicht gebundenen Kohlensäure noch stärker alkalisch. Ein Zusatz von $20^{\mathrm{ccm}} 10$ procent. Sodalösung auf den. Liter Nährgelatine genügt zwar nicht, um die Röthung des blauen Lakmuspapieres sofort zu beseitigen, nach dem Kochen tritt dieselbe aber allerdings nicht mehr oder nur noch schwach hervor. Es ist dieser Grad der Alkalität ein für das Wachsthum aller bekannten Mikroorganismen durchaus geeigneter, für Cholerabacillen thut man freilich besser, ihn noch zu steigern, für Typhusbacillen ihn zu vermindern, weil man dadurch vielen anderen Bakterien gegenüber einen Vortheil gewinnt. Man kann ohne Schaden für die Typhusmikroben die Nährgelatine ohne Zusatz von Alkali verwenden.

Durch diese Modification des Nährbodens allein erreicht man aber noch recht wenig. Wenn man denselben in der üblichen Weise mit dem verdächtigen Material, z. B. Wasser mischt und zu Plattenculturen verwendet, so kommen für die Diagnose des Typhus nur die oberflächlichen Colonieen, die bekanntlich allein charakteristisch, aber gegenüber den tiefliegenden in der erheblichen Minderheit sind, in Betracht. Dieses Missverhältniss kann man dadurch etwas ausgleichen, dass man grössere Platten für die gleiche Menge des Nährbodens zur Aussaat benutzt. Noch besser fährt man aber, wenn man das zu untersuchende Material direct auf möglichst grosse Oberflächen der Gelatine vertheilt. Ich verfahre jetzt in der Weise, dass ich die verflüssigte Gelatine mit einem Zusatz von 2 Tropfen 5 procent. Curbolsäurelösung auf je $10^{\mathrm{cm}}$ versehe, sie in eine Petri'sche Schale von möglichst grossem $\left(15^{\mathrm{cm}}\right)$ Durchmesser giesse und erstarren lasse. Dann bringe ich 20, 10, 5,2 bezw. 1 Tropfen (oder noch weniger, wenn nöthig) des zu untersuchenden Wassers auf die Platte und vertheile es mittels eines kleinen, im Dampftopf sterilisirten Haarpinsels auf derselben. Nach 24 (bis 48) Stunden Aufenthaltes bei $22^{\circ} \mathrm{C}$. werden die Platten mit schwacher Vergrösserung auf das Vorkommen von Typhuscolonieen hin untersucht. Versuche, die Gelatine durch Agar zu ersetzen, der dann bei $37^{\circ}$ gehalten werden kann, haben keine günstigen Resultate ergeben, da die Colonieen des Typhusbacillus auf der Agaroberfläche nicht so charakteristisch, sind, wie die auf Gelatine.

Auf diese Weise kann man, vorausgesetzt, dass die Zahl der im Cubikcentimeter vorhandenen Bakterien nicht zu beträchtlich ist, auch grössere Quantitäten Wasser untersuchen.

Es fragt sich, wie man am praktischsten weiter vorgeht, wenn man 
die ausgewachsenen Platten vor sich hat. Eine der wichtigsten Eigenschaften des Typhusbacillus ist, dass er auf der Gelatineoberfläche die bekannten, ziemlich zarten, weinblattartig umrandeten und geaderten Colonieen bildet. Namentlich die Aderung unterscheidet ihn von der grossen Zahl verwandter,. sog. typhusähnlicher Bakterien, im Speciellen von den gewöhnlichen Parasiten des Darmes, die meist unter dem Namen Bacterium coli commune zusammengeworfen werden. Je jünger die Colonieen sind, desto deutlicher ist diese Aderung, oder besser gesagt, Furchung. Der günstigste Termin zur Beobachtung derselben liegt zwischen 24 und 48 Stunden; später kann sie vollständig verschwinden. Leider sind zwei Momente geeignet, die Bedeutung des angegebenen Charakters in Frage zu stellen; erstens ist derselbe für den Typhusbacillus auch bei günstiger Reaction des Nährbodens nicht absolut constant, ${ }^{1}$ zweitens giebt es - besonders im Wasser - auch andere Bakterien, die ihn besitzen. Das kann uns jedoch nicht hindern, auf diese typische Colonieform vor Allem unser Augenmerk zu richten. Sie bleibt immerhin der beste Fingerzeig, der uns auf die Spur des gesuchten Mikroorganismus führen kann. Haben wir solche Colonieen auf den Platten, so könnten wir uns sofort durch die mikroskopische Prüfung auf Beweglichkeit, Form, Grösse und Färbbarkeit davon überzeugen, ob unser Verdacht noch besser begründet ist. Ich selbst habe allerdings mehrfach Gelegenheit gehabt, auf diesem Wege die Unschuld dẹs gefundenen Bacteriums zu constatiren. Einige Male war es ein unzweifelhafter Coccus, der die charakteristischen Colonieen gebildet hatte. Aber die Kriterien. die sich aus der mikroskopischen Untersuchung ergaben, sind nicht untrüglich: selbst Unbeweglichkeit spricht nicht mit Sicherheit gegen die Diagnose Typhusbacillus, wie mich neuere Erfahrungen gelehrt haben; unter Umständen, die vorläufig nicht näher zu definiren sind, können die Typhuserreger ihre Beweglichkeit einbüssen. Ganz ebenso beweglich können andererseits auch typhusähnliche Bakterien sein, sogar der Nachweis charakteristisch angeordneter Cilien ist bei letzteren gelungen.(Germano und Maurea). Für die morphologischen Verhältnisse gilt dasselbe: der Typhusbacillus selbst variirt in dieser Beziehung und hat ganz gleichgestaltete unschädliche Verwandte. Die Färbbarkeit endlich ist eine wenig bezeichnende Eigenschaft. Wir können zwar nicht mit Babes auch solche Bakterien als Typhusbacillen bezeichnen, die sich nach der Gram'schen Methode färben lassen, aber auch davon abgesehen, verhält sich die grosse Masse der typhusähnlichen Organismen gleich den ersteren.

\footnotetext{
1 Neaerdings habe ich das bei Isolirung des Typhusbacillus aus der Leiche wieder constatiren können.
} 
Am besten also ist es, wir lassen die mikroskopische Untersuchung vorläufig bei Seite und schreiten direct zur Isolirung der verdächtigen Colonieen. Wird doch die erstere praktisch schon unausführbar, wenn die Zahl der letzteren zu gross ist. Wir ersparen viel Zeit und Mühe, wenn wir statt dessen die betreffenden Colonieen einfach in Zuckeragar (Nähragar mit 2 Procent Traubenzucker) abstechen. Nach 24 Stunden ist die Auslese aus dem vorhandenen Material durch die Cultur selbst schon fast gethan. Entweder hat überhaupt kein Wachsthum stattgefunden: das beweist, dass die abgestochene Colonie einem gewöhnlichen Saprophyten angehört hat; oder es ist ein partielles Wachsthum, aber nur an der Oberfläche des Stichs, eingetreten, ein Beweis für die ausschliesslich ärobe Natur des betreffenden Bacteriums, ein ebenso strikter Beweis gegen Typhus; oder die Entwickelung ist auch in der Tiefe des Stichs eine gleichmässige gewesen, sie ist aber mit gleichzeitiger, mehr oder weniger reichlicher Gasbildung verlaufen: die allermeisten typhusähnlichen Bacillen besitzen diese Eigenschaft oder es fehlt endlich die Gasbildung trotz gleichmässigen Wachsthums längs des Stichs.

Nur sehr wenige Mikroorganismen ausser dem Typhusbacillus gehören zu dieser letateren Kategorie. ${ }^{1}$ Durch das genannte einfache Culturverfahren wird also die Auswahl unter den abgestochenen Colonieen ausserordentlich erleichtert: Jetzt muss man, um die Diagnose zu Ende zu führen, in erster Linie mit Berücksichtigung der oben angegebenen Verhältnisse, mikroskopisch untersuchen, ferner in alle üblichen Nährböden, Gelatine, Agar, Peptonbouillon, Mileh, Kartoffeln weiter übertragen. Der Gelatinestich ist nicht zu missen, da manchmal durch ihn erst einige Eigenschaften der Culturen zu Tage treten, die auf der Originalplatte nicht bemerkt worden sind, weil die Colonieen zu früh abgeimpft wurden: es kōnnen auch solche Colonieen, die in den ersten 2 bis 3 Tagen durchaus typhusähnlich aussehen, in späteren Stadien die Gelatine verflüssigen, oder sie können auch trotz ursprünglicher Farblosigkeit später Pigmente (grūne Fluorescenz) entwickeln. Die Agarstrichcultur ist wenig charakteristisch. Die Züchtung in Peptonbouillon ist wesentlich nöthig, um die Bildung oder das Fehlen von Indol festzustellen (Kitasato). Zwar wissen wir durch Germano und Maurea, dass ein nicht kleiner Theil der typhusähnlichen Bakterien gleich dem Typhuserreger selbst nicht im Stande ist, Indol zu entwickeln, doch bleibt die Probe darauf immer nceh ein gutes Kriterium, weil manche Bacillen, die in fast. allen übrigen Be-

${ }^{1}$ Vgl. Kruse und Pasquale. Diese Zeitschrift. Bd. XVI. S. 61. Im Wasser sind mir jetzt ähnliche Ausnahmen aufgestossen. 
ziehungen mit dem Typhusbacillus übereinstimmen, anf diese Weise leicht von ihm differenzirt werden können. (Kruse und Pasquale). ${ }^{1}$ Es ist nicht gleichgültig, wie die Probe angestellt wird. Die Zusammensetzung der Peptonbouillon hat einen ausschlaggebenden Einfluss darauf: wie es kommt, dass in manchen anscheinend gleich zusammengesetzten Nährlösungen die Indolbildung verzögert, in anderen beschleunigt wird,. bedarf der näheren Feststellung. Die Reaction der Bouillon ist nach meinen Versuchen ohne erhebliche Bedeutung, vorausgesetzt, dass sie überhaupt das Wachsthum gestattet. Sicher constatirt habe ich aber den Einfluss eines Gehaltes an Traubenzucker. Wenn derselbe über 0.25 Procent beträgt, so tritt keine Indolbildung mehr ein. Um die Reaction möglichst sicher zu erhalten, ist es nöthig, die Cultureu wenigstens eine Woche im Brütschrank bei $37^{\circ}$ $\mathrm{zu}$ halten. Je länger man wartet, desto gleichmässiger gelingt die Reaction. Es scheint da, wo überhaupt Indolbildung eintritt, dieselbe ein bei den verschiedenen Bakterien gleiches Maximum zu erreichen.

Für die Cultur in Milch gelten ähnliche Verhältnisse wie für die Indolreaction. Der Eintritt der Coagulation entscheidet gegen die Diagnose des Typhus, ihr Fehlen ist aber noch nicht für die Identität mit Typhus beweisend (vergl. Germano und Maurea).

Die Bedeutsamkeit der Kartoffelcultur für die Charakterisirung des Typhuserregers steht ausser allem Zweifel. Freilich wissen wir jetzt, dass das von Gaffky beschriebene typische Wachsthum auf Kartoffeln auch von anderen Bakterien entfaltet werden kann. ${ }^{1}$ Praktisch noch mehr in's Gewicht fällt die schon lange bekannte Thatsache, dass der Typhusbacillus auf vielen Kartoffeln selbst nicht typisch gedeiht. Um so werthvoller ist das Kriterium, das uns Germano und Maurea in der Paralleleultur auf Kartoffeln an die Hand gegeben haben: die letzteren mögen beschaffen sein wie sie wollen, d. h. ein typisches Wachsthum der Typhusbacillen gestatten oder nicht, stets gelingt es, wenn man auf die beiden Hälften einer und derselben Kartoffel einerseits eine Reincultur des Typhus und andererseits die verdächtige Cultur aussät, aus dem Vorhandensein oder dem Mangel von Differenzen zwischen den beiderseitigen Culturen zu entscheiden, ob der Verdacht auf Typhus. gerechtfertigt war oder nicht.

Was andere Methoden zur Differentialdiagnostik des Typhusbacillus anbetrifft, so ist auf die Arbeit von Germano und Maurea zu verweisen. Die aufgeführten haben bisher stets genügt, um typhusähnliche Bakterien von den wirklichen Erregern des Typhus zu unterscheiden.

A. a. 0 . 
Neuerdings hat allerdings $\mathrm{Pansini}^{1}$ einige interessante Beobachtungen mitgetheilt, durch die der Nachweis geführt erscheint, dass Mikroorganismen, die sich auf keine Weise vom Typhusbacillus differenciren lassen, bei menschlichen Affectionen vorkommen, die ausser Zusammenhang mit Abdominaltyphus stehen. Es handelt sich um drei Fälle von Leberabscess nach Dysenterie, von denen mindestens einer wahrscheinlich der durch Amöben verursachten Form zugehört hat. Sind das nun echte Typhusbacillen oder können wir sie nur nicht von solchen unterscheiden? Die Möglichkeit, dass erst der Versuch am Menschen die vorhandenen Differenzen hervortreten lassen könnte, ist nicht abzuleugnen.

Neben dem Erreger der Cholera und des Typhus steht als dritter im Bunde derjenige der Dysenterie. In einer jüngst erschienenen Arbeit ${ }^{2}$ haben wir es als wahrscheinlich hingestellt, dass es mindestens eine Form der Dysenterie gebe, die auf specifische Bakterien zurückzuführen sei, und zwar sei das gerade die epidemische Ruhr unserer Gegenden. Von Alters her schon ist für die Entstehung dieser Erkrankung das Wasser als Uebertragungsmittel in Anspruch genommen worden. Eindeutige Beweise dafür, die sich mit denen für Cholera und Typhus erbrachten vergleichen liessen, sind aber bisher nicht geliefert worden. Bei der Dysenterie wie bei den genannten Krankheiten hat der Umstand, dass zweifellos verschiedene Wege der Verbreitung neben einander bestehen können, die Aufklärung der ätiologischen Verhältnisse gehemmt. Dazu kommt noch in Betracht, dass die Ruhr bei uns seit der Zeit des Aufschwunges der bakteriologischen Forschungsmethode kaum eine grōssere epidemische $V$ Verbreitung gefunden hat.

Cholera, Typhus und Dysenterie sind wahrseheinlich nicht die einzigen, vorwiegend in dem Verdauungstractus localisirten Erkrankungen, die durch Wasser übertragen werden können, sie sind nur die symptomatologisch, anatomisch und äthiologisch am besten charakterisirten und durch ihre Bedeutung für Leben und Gesundheit praktisch wichtigsten Affectionen. In der Litteratur sind eine ganze Anzahl kleiner Epidemieen von Mlagendarmcatarrhen beschrieben worden, die auf den Genuss eines bestimmten Wassers zurückgeführt werden dürften. ${ }^{3}$ Es liegt näher, an organisirte Schädlichkeiten, an specifisch pathogene Bakterien, die wir noch nicht kennen, hierbei zu denken, als an chemische Gifte. Möglich wäre es auch, dass nicht eigentlich pathogene Mikroorganismen, sondern einfache Gährungserreger, die in grösseren Mengen in's Wasser gelangt sind, unter Umständen Erkrankungen des Verdauungscanals er-

1 Pansini. Riforma medica. 1893. Nr. 95-99.

' Kruse und Pasquale, a. a. 0.

3 Vgl. z. B. Uffelmann's Jahresberichte. 1883 u. 1884. Zeitschr. f. Il ggiene. XVII. 
zeugen könnten; bei Kindern, die ihre Milch mit Wasser gemischt geniessen, ist namentlich ein solcher Effect denkbar.

Dass bei der Verbreitung von Zoonosen das Wasser theils direct, theils indirect eine erhebliche Rolle spielt, kann nicht bezweifelt werden. Für den Menschen käme von denselben nur der Milzbrand in Betracht, in der als Mycosis intestinalis bekannten Form. Indessen sind Fälle, in denen menschlicher Milzbrand durch Wassergenuss verursacht worden wäre, noch nicht beschrieben worden.

Schädliche Bakterien werden im Allgemeinen nur in günstigen Fällen und nur durch speciell daraufhin gerichtete Untersuchungen im Wasser zu constatiren sein; stets sind im Wasser beliebigen Ursprunges unschädliche Bakterien in grösserer oder geringerer Menge vorhanden und gerade diese sind es, die für die gewöhnliche bakteriologische Analyse mittels Plattencultur allein nachweisbar sind. Trotzdem nun dio Unschädlichkeit dieser Mikroorganismen von Niemand angezweifelt wird, hat man sich bemüht, ihren Nachweis zu Folgerungen bezüglich der hygienischen Brauchbarkeit eines Wassers zu benutzen. Drei Momente sind nacheinander in den Vordergrund des Interesses gerückt worden, nämlich erstens die absolute Zahl der in der Volumeneinheit des Wassers (Cubikcentimeter) enthaltenen Mikroorganismen, zweitens die Zahl der verschiedenen Arten von darin vertretenen Bakterien und drittens deren specifische Beschaffenheit. Der Gedanke, dass ein Zuviel von Bakterien bezw. Bakterienspecies auf das Vorhandensein von directen Zuflüssen deute und dass einzelne Mikroorganismen die besondere Gefährlichkeit solcher Zuflüsse beweisen, liegt dieser Beurtheilungsmethode zu Grunde. Lassen wir den dritten Punkt vorläufig ausser Betracht, so ist es unzweifelhaft, dass eine hohe Zahl von Keimen oder Species aucl andere Ursachen haben kann, als Verunreinigung des Wassers durch directe $\mathrm{Zu}$ flüsse. Auch bei den bestgeschützten Brunnen, z. B. Abyssiniern kann die Menge der im Cubikcentimeter vorhandenen Mikroorganismen unter Umständen erheblich steigen. Diese Vermehrung hängt aber nur von einem stärkeren Zutritt der innerhalb der Pumpenröhren oder an den Schachtwänden wuchernden Bakterien $a b$. Um diese Fehlerquelle zu beseitigen, hat man die Vorschrift gegeben, den Brunnen geraume Zeit vor der bakteriologischen Analyse regelmässig zu benutzen und unmittelbar vor derselben wenigstens fünf Minuten abzupumpen. Dass diese Regeln aljer in der Praxis nicht immer ihren Zweck erreichen, ist bekannt. Nehmen wir indessen einmal an, dass die erböhte Zahl der Bakterien und Bakterienspecies von einer Verunreinigung des Wassers von aussen herrühre, so ist damit noch nichts gegen dessen hygienische Zulässigkeit gesagt. Es giebt zahlreiche bakterienführende Zuflüsse unver- 
dächtiger Natur. Das Regenwasser, das in Cisternen sich sammelt, alle offenen Wasserläufe in unbewohnten Gegenden sind reich an Mikroorganismen, obwohl gänzlich gefahrlos. Auch bei Brunnen, die in der Nähe menschlicher Wohnungen errichtet sind, können ähnliche Verhältnisse bestehen. Dieselben können z. B. dem unschädlichen Regenwasser directen Zutritt gestatten, obwohl andere Zuflüsse durch die Fassung des Brunnenrandes so gut wie ausgeschlossen sind, sie können aber auch trotz schlechter Abdichtung des letzteren, also trotzdem beliebige seitliche Zufiüsse nicht abgehalten werden, hygienisch zulässig sein, wenn der Kessel z. B. entfernt von der Pumpe und dem Ablauf des Schmutzwassers und in geschützter Umgebung, z. B. in einem abgezäunten Theil des Gartens, liegt. Der bakteriologischen Analyse müssen solche Wässer allerdings als recht schlechte erscheinen, weil sie an Bakterien reich zu sein pflegen.

Auf der_anderen Seite wäre es oft recht trügerisch, aus der Keimarmuth eines Wassers den Schluss zu ziehen, dass dasselbe vom gesundheitlichen Standpunkte aus nicht zu beanstanden wäre, weil die niedrige Bakterienzahl das Fehlen directer Zuflüsse bewiese. Das Verhältniss, in dem die absolute Wassercapacität eines Brunnens, die Schnelligkeit und Reichlichkeit der Strömung des den Brunnen speisenden Grundwassers, und endlich die Grösse des Wasserverbrauches zu der Menge der bakterienführenden Zuflüsse steht, bestimmt natürlich die Zahl der in der Volumeneinheit vorhandenen Keime. Es können sogar ganz regelmässig solche Verunreinigungen bestehen, ohne dass die bakteriologische Analyse einen bestimmten Verdacht begründete. Die Anlage mancher Brunnen ist nun aber derartig, 'dass sie nicht regelmässige, sondern nur periodische Zuflüsse gestattet. Es kann das in verschiedener Weise mit der Witterung zusammenhängen: unter Umständen ist es eine langanhaltende Trockenheit, die direct den Boden eröffnet, durch welche Zuflüsse in den Schacht gelangen, gerade umgekehrt können aber auch starke Niederschläge schädlich wirken, indem sie neue Communicationen zwischen dem Kessel und der Aussenwelt herstellen. Weil man solche Einflüsse der Witterung des Oefteren im bakteriologischen Befund nachweisen konnte, hat man wohl die Regel aufgestellt, ein Brunnenwasser unter verschiedenen meteorologischen Verhältnissen zu untersuchen. Dass aus dem Ausfall der bakteriologischen Analyse in solchen Fällen aber auch nur unsichere Schlüsse gezogen werden können, ist zweifellos. Steigt z. B. nach starken Niederschlägen der Keimgehalt eines Brunnenwassers, so spricht das wohl für Zuflüsse, sie können aber hygienisch ganz indifferent sein. Den Fall, dass die Anlage des Brunnens nur unverdächtigem Meteorwasser den directen Eintritt in den Schacht gestattet, haben wir schon erwähnt, dasselbe braucht aber bei guter Verfassung der Brunnenbedeckung nicht 
einmal direct in den Schacht zu fliessen, sondern - bei gehöriger Durchfeuchtung der oberen Bodenschichten - erst nach Filtration durch das umgebende Terrain. Trotzdem das so in den Brunnen von oben bineingepresste Wasser an sich keimfrei ist, bewirkt es an den Wänden des Schachtes hinablaufend, die Ablösung von dort immer zahlreich wuchernden Bakterien, die sich dann dem Brunnenwasser beimischen. Auf diese Weise dürfte sich die Steigerung der Keimzahl, die ich bei gänzlich unterirdischen, vorwurfsfreien Kesselbrunnenanlagen nach starken Niederschlägen bemerkt habe, wohl am ehesten erklären lassen.

Wie steht es nun mit denjenigen Bakterienarten, die für gewisse als gefährlich angesehene Zuflüsse specifisch sein sollen? Man rechnet dazu erstens Fäulnisserreger im Allgemeinen. Ist deren Existenz im Wasser aber ein Beweis, dass dasselbe direct mit faulenden Stoffen verunreinigt wird? Ganz und gar nicht! Allgemein bekannt ist es, dass unter den exquisiten Wasserbewohnern gerade die Arten, die Peptonisirungsvermögen besitzen, in der Mehrzahl sind. Weniger bekannt, aber leicht zu beweisen ist es, dass sehr viele ron ihnen auch Indolbildner sind. Wir haben hier schon zwei Gruppen von Bakterien, die das Eiweissmolekül anzugreifen im Stande sind. Von den Indolbildnern zu den Agentien der echten stinkenden Fäulniss ist nur ein weiterer Schritt. Auch solche Mikroorganismen sind in jedem, auch dem besten Wasser vorhanden. Nehme man Proben von Wässern der verschiedensten Herkunft, z. B. auch aus Rohrbrunnen und bringe sie mit Nährgelatine vermischt auf Platten oder verarbeite man sie, um Luftkeime auszuschliessen, in Rollröhrchen. Die einen werden früher die Spuren echter Fäulniss geben, die anderen später; bei keiner Wasserprobe wird dies Endresultat ausbleiben: mit Mengen von wenigen $\mathrm{Ccm}$ habe ich es stets erhalten. Verwunderung erregen kann eigentlich dieses Ergebniss nicht. Jedes Wasser, auch wenn es ursprünglich keimfrei ist und keine Zuflüsse von aussen empfängt, wird durch die Mittel, die zur Entnahme dienen, mit Bakterien verunreinigt, und zwar findet diese Verunreinigung auch bei der besten Brunnenanlage constant und gleichmässig statt, da an den Wänden der Pumpenröhren stets zahlreiche Mikroorganismen Gelegenheit finden, sich zu entwickeln und frei in das Wasser zu gelangen. So gut wie niemals werden das Bakterien sein, die nur im.Wasser zu vegetiren vermögen, obligate Wasserbakterien, denn sie verdanken ibre Anwesenheit daselbst ja nur zufälligen Verbindungen des Wassers mit der Aussenwelt. Sie gehören mit einem Worte zu den gewöhnlichen Saprophyten. Dass nicht alle letzteren sich dem meist dürftigen Nährboden zu accommodiren vermögen, ist selbstverständlich, immerhin scheint doch das Anpassungsvermögen recht weit zu gehen. Nach den interessanten Versuchsergeb- 
nissen Wolffhügel und Riedels z. B. können selbst die Cholerabacillen durch längeren Aufenthalt im Wasser zu einer Art von Wasserbakterien herangezüchtet werden, die schliesslich viel besser in demselben vegetiren als die ursprünglich eingesäten Individuen.

Eine noch grössere Bedeutung als den Fäulnisserregern messen viele Autoren der Anwesenheit des "bacterium coli commune" im Wasser zu. Dasselbe soll direct auf Verunreinigung mit menschlichen Fäcalien hinweisen. Wenn nun diejenigen, die dieses Kriterium aufstellen und bei der Wasseranalyse praktisch verwerthen, eine auch nur einigermassen sicher begründete Bakterienspecies darunter verständen und sich Mühe gäben, ein im Wasser gefundenes Bacterium mit allen Mitteln der jetzt recht complicirten Diagnostik mit jenem Typus zu ilentificiren, so würde das bacterium coli wohl seltener gefunden werden. Leider ist man im Allgemeinen sehr im Unklaren darüber, was man unter diesem Namen zu verstehen hat, es ist weniger eine Art als ein Gattungsbegriff, der schon durch eine kleine Zahl ron Charakteren, nämlich gewisse übereinstimmende morphologische Verhältnisse und Aehnlichkeit des Wachsthums in den gewöhnlichen Nährböden bestimmt wird.

In dieser Weise aufgefasst ist das bacterium coli aber in keiner Weise charakteristisch für die Fäces der Menschen oder Thiere. Solche Bakterien finden sich überall, in der Luft, im Boden, im Wasser allerverschiedensten Ursprunges. Selbst wenn man noch zu den genannten einige andere unterscheidende Merkmale hinzufügt, nämlich betreffend das Verhalten in Milch und zuckerhaltigen Nährsubstraten, wird noch wenig gewonnen. Auch Mikroorganismen mit diesen Eigenschaften sind sehr verbreitet. Wie wäre es sonst wohl zu verstehen, dass die ersten Bakterien, die in den Fäces von neugeborenen Kindern mit absoluter Regelmässigkeit auftreten, eben zu dem so charakterisirten bacterium coli gehören, wenn ihre Keime nicht die am weitesten verbreiteten Saprophyten darstellten? Dementsprechend fehlen sie auch oft genug nicht in Wässern, die nicht einmal anderen Verunreinigungen, geschweige denn solchen von Fäcalien ausgesetzt sind. Man kann sich von ihrer Anwesenheit manchmal schon durch die gewöhnliche Plattenmethode überzeugen, andere Male lassen sie sich durch das Verfahren, das bei Gelegenheit des Typhusnachweises im Wasser besprochen wurde, heranzüchten.

Es braucht kaum noch daran erinnert zu werden, welche Fehlerquellen für die bakteriologische Analyse aus der Art der Entnahme, der Conservirung und Versendung der Wasserprobe entstehen, sobald nicht eine sachverständige Ueberwachung all dieser Proceduren möglich ist. Cnser Trtheil lautet freilich auch ohnedies schon ungünstig genug für die genannte Methode. Nur wenn man nichts anderes zur Verfügung. 
hat als die Wasserprobe selbst, kann man allenfalls magere und recht unsichere Schlüsse aus der bakteriologischen Untersuchung ziehen: bei geringer Keimzahl ist das Wasser vielleicht gut, bei grosser vielleicht schlecht. Bei wiederholter Prüfung von Proben desselben Ursprunges, die natürlich immer noch einer einmaligen vorzuziehen ist, macht man allzu oft die unliebsame Beobachtung, dass die Resultate inconstant sind: es hat das aber wenigstens das eine Gute, dass man von der Unsicherheit der gezogenen Schlüsse selbst überzeugt wird. Um sich praktisch zu helfen, hat man zu der Aushülfe der Grenzzahlen gegriffen, die natürlich sowohl für die erlaubte Menge der Bakterien als für die statthafte Artenzahl ganz willkürlich gewählt sind. Durchschnittszahlen sollen also in einer so wichtigen Frage, wie die der hygienischen Brauchbarkeit eines bestimmten Wassers entscheiden, obwohl gerade meist das sachverständige Urtheil verlangt wird, weil man einen mehr oder weniger bestimmten Verdacht auf das betreffende Wasser hat! Nur ein Gutachten, das auf genauer Berücksichtigung aller möglichen Infectionsquellen begründet ist, kann da helfen, und ein solches ist ohne Kenntniss der örtlichen Verhältnisse nicht möglich. Viel wichtiger als jede bakteriologische Analyse ist schon eine genaue Beschreibung der Brunnenanlage selbst, der Art ihrer Benutzung und ihrer Umgebung. Selbstverständlich ist ein ganz sicheres Urtheil nur zu gewinnen, wenn der Sachverständige Gelegenheit hat, selbst die Besichtigung an Ort und Stelle vorzunehmen. Immerhin ist durch präcise Fragestellung an eine zuverlässige Person vom 0rt auch schon manches zu erreichen. Erst in zweiter Linie kommt dann in Frage, ob nicht die bakteriologische Analyse neben der Localinspection noch einige Vortheile bieten kann. Es ist das nicht ganz abzuleugnen. Wenn man z. B. bei anscheinend tadelloser Anlage eine constant hohe Keimzahl des.Brunnenwassers findet, die man nicht auf nebensächliche Verhältnisse zurückführen kann, wird man sich vielleicht bewogen fühlen, um so gründlicher Obacht zu geben und an die Brunnendichtung um so strengere Anforderungen $\mathrm{zu}$ stellen.

Ihrem Zwecke wie ihrem Werthe nach von der gewöhnlichen bakteriologischen Wasseranalyse ganz zu scheiden, ist diejenige Untersuchung des Wassers, dieunternommen wird, um die Reinigung irgend eines stark mit Bakterien gemengten Wassers zu prüfen. Wir gehen hier von einem bekannten Material aus, kennen den Process der Reinigung, sei es, dass derselbe in einem Desinfections-, Niederschlags- oder Filtrationsverfahren besteht, und haben nun das erreichte Resultat zu beurtheilen. Schon wenn wir uns hier einfach der zahlenmässigen Vergleichung des Bakteriengehaltes bedienen, erhalten wir einen brauchbaren Maassstab für den erzielten Effect. 
Vollkommen ist derselbe nur, wenn das gereinigte Wasser keimfrei ist; im Grossen wird dieses Ergebniss aus verschiedenen Gründen nie erreicht. Es. handelt sich dann festzustellen, ob die im gereinigten Wasser vorhandenen Keime nicht wenigstens zum Theil aus dem Rohmaterial direct herstammen, ein Verhalten, das im Princip verhütet werden sollte. Bis jetzt besitzen wir leider noch nicht zureichende Kriterien, um diese Frage mit Bestimmtheit zu entscheiden und helfen uns da z. B. bei der Sandfiltration mit der Angabe ron Grenzzahlen, die zwar eine gewisse praktische Begründung für sich haben, uns aber keine absolute Sicherheit geben.

Eine andere Gruppe mikroskopischer Organismen, die neben den Bakterien als Krankheitserreger in Betracht kommen können, sind die Protozoen. Sicher pathogen für den Menschen sind das Plasmodium malariae und die Amoeba dysenteriae. Ob die Malaria durch Wassergenuss erzeugt werden kann, ist sehr zweifelhaft, trotzdem in Gegenden, wo sie einheimisch ist, der Glaube daran allgemein herrscht. Während es aber zahllose Beispiele für die Uebertragung auf anderem Wege giebt, sehen wir uns rergebens nach sicheren Beweisen für die Wassertheorie um. Seit langer Zeit pflegt der Fall ron Boudin ${ }^{1}$ citirt zu werden, in dem es sich um eine Wechselfieberepidemie gehandelt hat, die unter der NIannschaft des Schiffes Argo in Folge des Genusses ron schlechtem Trinkwasser auf hoher See ausgebrochen sein soll. Neuerdings hat Senise ${ }^{2}$ rom italienischen Festland über eine ähnliche, angeblich durch Trinkwasser rerursachte Epidemie berichtet. In beiden Fällen fehlt der exakte Nachweis, dass die Erkrankungen wirklich als Infectionen mit Plasmodien, den jetzt anerkannten Erregern der Malaria, aufzufassen seien. Wichtiger ist aber die Thatsache, dass in einigen direct zur Entscheidung dieser Frage angestellten Untersuchungsresten ron Celli, Marino ${ }^{3}$ und Zeri ${ }^{4}$ selbst reichliches und fortgesetztes Trinken von Sumpfwasser kęinen Nalariaanfall auszulösen im Stande war.

Anders steht die Sache bei der in heissen Ländern endemisch, bei uns nur sporadisch vorkommenden Dysenterie. Zwar ist die Amöbe, die als die Ursache dieser Krankheitsform angesehen werden muss, bisher noch nicht im Wasser nachgewiesen worden; directe Experimente haben sogar ergeben, dass die regetatiren, im Darm des Menschen

${ }^{1}$ Hirsch. Historisch-geographische Pathologie.

2 Senise. Secondo congresso della società ital. di medic. intern. Roma 1889. Ref. im Centralblatt fürBakteriologie. Bd. VIII. S. 403.

3 Marino. Congresso med. di Roma 1890. Dell' acqua dei luoghi malarici. Citirt nach M an naberg. Malariaparasiten. Wien 1893.

${ }^{4}$ Zeri. Annali dell' istituto d'igiene sperimentale dell' Università di Roma. 1890. Vol. II. Ref. in Hygienische Rundschau. 1891. 'S. 599. 
lebenden Zustände derselben als solche nicht einmal im Wasser weiter existiren können, ${ }^{1}$ indessen ist dadurch nicht ausgeschlossen, dass ihre Dauerformen durch das Wasser verbreitet werden könnten. In der That sprechen die Erfahrungen der sachverständigen Aerzte für die Realität dieses Infectionsmodus.

Andere Protozoën, nämlich Flagellaten und eine Wimperinfusorie, das Balantidium coli, sind höchstens verdächtig, ${ }^{2}$ unter Umständen Krankheitserscheinungen beim Menschen hervorzurufen. Sehr wohl möglich ist es, dass auch diese Parasiten durch Termittelung des Trinkwassers in den Darm gelangen.

Nachgewiesen ist aber deren Vorkommen im Wasser auch noch nicht, obwohl ähnliche Mikroorganismen darin schon lange bekannt sind. Trotz der nachweislich unschädlichen Natur dieser letzteren hat man geglaubt, auf ihr Vorkommen im Wasser vom hygienischen Standpunkt aus Werth legen zu müssen, weil man sie als Indicatoren einer schädlichen Beschaffenheit des Wassers ansah. Es ist das eine specifisch Breslauer Theorie, die von F. Cohn, ${ }^{3} \mathrm{Hirt}^{4}$ und $\mathrm{Hulwa} \mathrm{a}^{5}$ vertreten worden ist und auch jetzt noch hier bei Praktikern gilt. Ich kann mich darüber sẹr kurz fassen, es gilt von den Protozoën im Wasser dasselbe, was von den unschädlichen Bakterien oben gesagt worden ist. Sie kommen in jedem Wasser vor, auch in Abyssinierbrunnen, die ein sogenanntes tadelloses Wasser führen. Ihre Menge hängt weder direct von der chemischen Beschaffenheit des Wassers ab, noch von der Existenz von Zuflüssen von aussen. Bemerkenswerther Weise habe ich unter 16 Brunnenwässern in einem, das in seinem Gehalt an Stadtlaugebestandtheilen etwa in der Mitte stand und gegen Verunreinigungen durch directe Zuflüsse am besten geschützt war, die meisten Protozoën gefunden. Irgend einen Werth kann ich daher der Untersuchung auf diese Organismen nicht beilegen. Wenn freilich ihre Menge im Wasser so sehr steigt, dass dasselbe dadurch getrübt erscheint, so ist es zum Gebrauch natürlich nicht zu empfehlen, einfach aus dem Grunde, weil es für den Gesichtssinn, Geruch und Geschmack unappetitlich ist. Des Mikroskopes bedarf man nicht zur Erkennung dieser Eigenschaften. Deswegen wird man kaum Gelegenheit haben, der Frage nahe zu treten, ob solches Wasser auch gesundheits-

${ }^{1}$ Kruse u. Pasquale, a. a. 0.

2 Vgl. Kruse, Der gegenwärtige Stand unserer Kenntnisse von den parasitären Protozoën. Hygienische Rundschau. 1892. S. 379 u. 380.

${ }^{3}$ F. Cohn. Beiträge zur Biologie der Pflanzen. Bd. I. S. 113.

${ }^{4}$ Hirt. Zeitschr. f. Biologie. Bd. XV. S. 91. - System der Gesundheitspflege.

${ }^{5} \mathrm{Hulwa}$. Centralblatt für allgemeine Gesundheitspflege. (Ergänzungshefte.)

Bd. I. Hft. 2. 
schädigend wirken kann. Die Möglichkeit ist a priori nicht zu leugnen, weil dasselbe ein Gemisch faulender Substanzen von nicht geringer Concentration ist.

Was eine dritte Gruppe mikroskopischer Bestandtheile des Wassers, nämlich die Eier und Embryonen von parasitischen Würmern anbetrifft, so ist den bekannten Thatsachen nichts Neues hinzuzufügen. Der directe Nachweis solcher organischen Formen im Wasser, der zwar selten genug gelingen wird, genügt natürlich, um die Verwendbarkeit desselben vom hygienisehen Standpunkte auszuschliessen. Praktisch kommt die Tebertragung von Bandwürmern (Blasenwürmern) durch das Wasser bei uns kaum, die von Spulwürmern schon eher in Betracht, in heissen Ländern treten als häufige gefährliche Insassen des Wassers auf: die Eier des A n chy lostomum duodenale, das sich bei uns nur in vereinzelten Epidemieen gezeigt hat, die Eier und Embryonen von Distoma haematobium, der Filaria medinensis und der Filaria sanguinis.

\section{Schl uss.}

Die Resultate der vorliegenden Cntersuchungen können in folgenden Thesen zusammengefasst werden:

1. Die Ergebnisse der Prüfung des zum Genuss bestimmten Wassers durch die Sinne (Gesicht, Geruch, Geschmack, Temperatursinn) sind von nicht zu unterschätzender hygienischer Bedeutung.

2. Die chemische Untersuchung hat entschieden geringeren Werth und ist für die praktische Hygiene fast entbehrlich. Nur die Härtebestimmung ist von Nutzen, da der Gehalt des Wassers an Erdsalzen gesundheitlich nicht indifferent ist und indirect durch seine ökonomischen Beziehungen das hygienische Interesse in Anspruch nimmt. In besonders rerdächtigen Fällen ist die Prüfung auf chemısche (metallische) Gifte nothwendig. Die organischen Stoffe des Wassers sind hingegen als unschädlich zu betrachten.

3. Die gewöhnliche bakteriologische Wasseranalyse berechtigt nicht zu zuverlässigen Schlüssen bezüglich der gesundheitlichen Zulässigkeit eines Wassers. Die absolute Keimzahl, die Zahl der verschiedenen Arten, der vermeintliche Nachweis specifischer Bakterien als Indicatoren menschlicher Abfallstoffe, alles das sind höchst trügerische Kriterien. Nicht zu entbehren ist dagegen die bakteriologische Zählmethode bei der Controle der Leistungen von Einrichtungen zur Reinigung des Wassers (namentlich Filter im Grossen und Kleinen).

4. Die Untersuchung des Wassers auf Krankheitserreger, insbesondere auf Cholera- und Typhusbakterien besitzt ein hohes wissenschaftliches 
Interesse, indessen hat man trotz der Vervollkommnung der Methodik auf den Nachweis derselben nicht zu warten, um ein Wasser für infectionsverdächtig zu erklären. Die Möglichkeit oder Wahrscheinlichkeit, dass solche Mikroorganismen in das Wasser hineingelangt sind, muss dazu genügen, da experimentell feststeht, dass die Lebensfähigkeit der genannten Parasiten im Wasser, den früheren Vorstellungen entgegen, eine recht bedeutende ist.

5. Wesentlich entscheidend für die hygienische Beurtheilung eines Wassers ist die sorgfältige Berücksichtigung des Ursprunges der Wasserquelle und der zur Entnahme des Wassers dienenden Anlage.

6. Es ist ganz dringend $\mathrm{zu}$ wünschen, dass die alte Tradition, nach der man Wașser durch Chemiker und Apotheker oder durch bakteriologische Laboratorien beurtheilen lässt, einer richtigen Anschauungsweise Platz mache. Nur hygienisch gebildete Sachverständige sind dazu berufen.

7. Die Hauptforderung, die von der Hygiene an eine Wasserversorgung $\mathrm{zu}$ stellen ist, ist die, dass entweder ein von Infectionsstoffen freies Wasser gewählt wird und die Entnahmestelle gegen Verunreinigung mit solchen geschützt ist oder dass die Reinigung des Wassers durch besondere mit der Entnahme verbundene Einrichtungen die Gewähr bietet, dass Infectionsstoffe dadurch ausgeschlossen werden. Der erste Weg ist. der sicherere.

8. Für centrale Wasserversorgungen wäre daraus $\mathrm{zu}$ folgern, dass man vom filtrirten Flusswasser, wenn möglich, zum Grund- oder Quellwasser überginge. Man erreicht dadurch den doppelten Vortheil, dass man das Wasser nicht nur zu einem gesunden Nahrungsmittel, sondern zu einem wirklichen Genussmittel macht. Die aus dem Eisengehalt manchen Grundwassers sich ergebenden Schwierigkeiten lassen sich gerade bei centralen Versorgungen durch neuere Enteisenungsverfahren heben.

9. Für die locale Wasserversorgung kommt rom hygienischen Standpunkt allein diejenige durch Brunnen (oder Cisternen) in Betracht. Auf die Anlage derselben ist mehr als bisher auch von sanitätspolizeilicher Seite aus Obacht zu geben. ${ }^{1}$ Von Rohrbrunnen ganz abgesehen, sind auch für Kesselanlagen verschiedene Systeme angängig.

10. Zwar ist die Beschaffenheit des Gebrauchwassers hygienisch nicht als unwesentlich anzusehen, immerhin spielt das Trinkwasser bei Infectionen eine bei weitem wichtigere Rolle. Aus praktischen Gründen empfiehlt es sich, die principiell berechtigte Gegnerschaft gegen eine gemischte Wasserversorgung nicht allzu weit zu treiben.

1 Der Entwurf zum Reichs-Seuchengesetz sieht eine staatliche Ueberwachung der Einrichtungen zur Versorgung mit Trink-oder Wirthschaftswasser vor. 